\title{
A state-of-the-art synthesis on female genital mutilation/cutting: What do we know now?
}

Bettina Shell-Duncan

Reshma Naik

Charlotte Feldman-Jacobs

Follow this and additional works at: https://knowledgecommons.popcouncil.org/departments_sbsr-rh

Part of the Demography, Population, and Ecology Commons, Family, Life Course, and Society Commons, International Public Health Commons, Maternal and Child Health Commons, Sociology of Culture Commons, and the Women's Health Commons How does access to this work benefit you? Let us know!

\section{Recommended Citation}

Shell-Duncan, Bettina, Reshma Naik, and Charlotte Feldman-Jacobs. 2016. "A state-of-the-art synthesis on female genital mutilation/cutting: What do we know now?" New York: Population Council. 


\section{Evidence to End FGM/C}

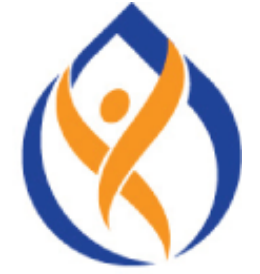

Research to Help Girls and Women Thrive

\section{A STATE-OF-THE-ART SYNTHESIS ON FEMALE GENITAL MUTILATION/CUTTING \\ WHAT DO WE KNOW NOW? \\ OCTOBER 2016 (UPDATE)}




\title{
A STATE-OF-THE-ART SYNTHESIS ON FEMALE GENITAL MUTILATION/CUTTING WHAT DO WE KNOW NOW? \\ OCTOBER 2016 (UPDATE)
}

\author{
BETTINA SHELL-DUNCAN \\ University of Washington \\ RESHMA NAIK \\ CHARLOTTE FELDMAN-JACOBS \\ Population Reference Bureau
}


Evidence to End FGM/C: Research to Help Women Thrive generates evidence to inform and influence investments, policies, and programs for ending female genital mutilation/cutting in different contexts.

Evidence to End FGM/C: Research to Help Women Thrive is led by the Population Council, Nairobi in partnership with the Africa Coordination Centre for Abandonment of Female Genital Mutilation/Cutting, Kenya (ACCAF); Gender and Reproductive Health \& Rights Resource Centre, Sudan (GRACE); Global Research and Advocacy Group, Senegal (GRAG); Population Council, Nigeria; Population Council, Egypt; Population Council, Ethiopia; MannionDaniels, Ltd. (MD); Population Reference Bureau (PRB); University of California, San Diego (Dr. Gerry Mackie); and University of Washington, Seattle (Dr. Bettina Shell-Duncan).

POPULATION The Population Council confronts critical health and development issues-from COUNCIL

Ideas. Evidence. Impact. stopping the spread of HIV to improving reproductive health and ensuring that young people lead full and productive lives. Through biomedical, social science, and public health research in 50 countries, we work with our partners to deliver solutions that lead to more effective policies, programs, and technologies that improve lives around the world. Established in 1952 and headquartered in New York, the Council is a nongovernmental, nonprofit organization governed by an international board of trustees. popcouncil.org

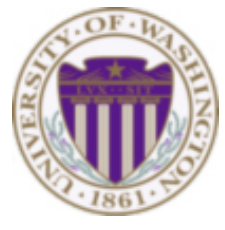

The University of Washington is one of the world's preeminent public universities. Our impact on individuals, our region, and the world is profound — whether we are launching young people into a boundless future or confronting the grand challenges of our time through undaunted research and scholarship. We turn ideas into impact and transform lives and our world. washington.edu

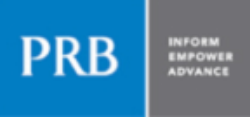

The Population Reference Bureau informs people around the world about population, health, and the environment, and empowers them to use that information to advance the well-being of current and future generations. prb.org

Suggested citation: Shell-Duncan, Bettina, Reshma Naik, and Charlotte Feldman-Jacobs. 2016. "A Stateof-Art-Synthesis of Female Genital Mutilation/Cutting: What Do We Know Now? October 2016," Evidence to End FGM/C: Research to Help Women Thrive. New York: Population Council. http://www.popcouncil.org/ EvidencetoEndFGM-C.

Please address any inquiries about Evidence to End FGM/C: Research to Help Women Thrive to: Dr. Jacinta Muteshi, Project Director, jmuteshi@popcouncil.org

(C) 2016 The Population Council, Inc.

Funded by:

This document is an output from a project funded by UK Aid from the UK government for the TH benefit of developing countries. However, the views expressed and information contained in it are not necessarily those of, or endorsed by, the UK government, which can accept no responsibility for such views or information or for any reliance placed on them. 


\section{Acknowledgments}

This report was written by Bettina Shell-Duncan, professor in the Department of Anthropology at the University of Washington; Reshma Naik, senior policy analyst at the Population Reference Bureau (PRB); and Charlotte Feldman-Jacobs, associate vice president at PRB. The authors of this report are grateful for insightful review and comments by the Population Council's senior management team on Evidence to End FGM/C: Research to Help Women Thrive: Jacinta Muteshi, project director; and Carolyne Njue, senior technical advisor. Special thanks also to other reviewers, particularly lan Askew, director, Department of Reproductive Health and Research at the World Health Organization (formerly of the Population Council), P. Stanley Yoder, independent consultant, and expert reviewers at DFID. The authors also appreciate the support of PRB's Heidi Worley, editorial director, and Nicole LaGrone, program assistant. Computing support and grant administration through the Center for the Study of Demography and Ecology at University of Washington was supported by the Eunice Kennedy Shriver National Institute of Health and Human Development award number 5R24HD042828.

(C) 2016 The Population Council, Inc. All rights reserved. 


\section{Table of Contents}

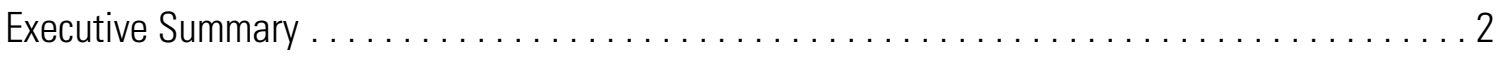

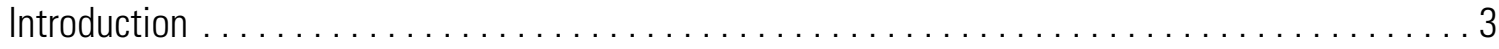

What Are the Main Sources of Data on FGM/C? ........................ 5

Where Is FGM/C Practiced and Among How Many? ......................... 6

Number of Girls and Women Affected by or at Risk of FGM/C . . . . . . . . . . . . . . 7

The Context Around FGM/C . . . . . . . . . . . . . . . . . . . . . . . . . . 8

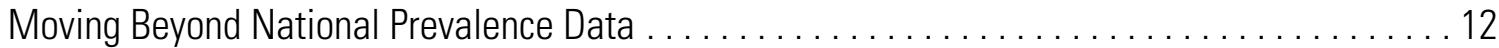

Opportunities for Abandonment ...................................... 20

Is Support Shifting? ......................................... 23

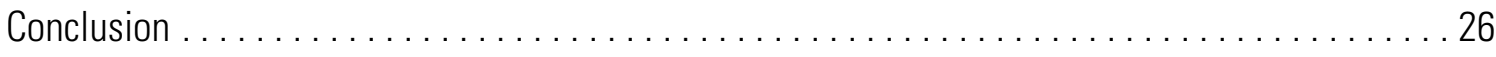

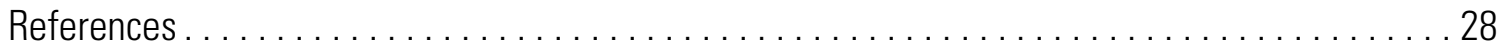




\section{Executive Summary}

Efforts to end female genital mutilation/cutting (FGM/C) are a rising priority on many national and global agendas. Thus it is imperative to have a clear understanding of the scale and scope of the practice, and where it occurs, as well as the dynamics of change and the broader context surrounding it. This state-ofthe-art synthesis offers a snapshot of the most recent data available as of July 2016 and the most relevant contextual information on key FGM/C issues in clear, non-technical language that can help inform policymakers, donors, programme planners, and other key stakeholders.

Nationally representative data on the prevalence of FGM/C among girls and women ages 15-49 are available for 29 countries: Twenty-seven countries in Africa plus Yemen and Iraq. Fifteen of these countries show no clear evidence of progress, while in 14 countries, the practice appears to be declining. Two out of three affected women live in just four countries-Egypt, Ethiopia, Nigeria, and Sudan. In Indonesia, nationally representative data on $\mathrm{FGM} / \mathrm{C}$ prevalence is available but only for girls under the age of 12 years. $\mathrm{FGM} / \mathrm{C}$ also occurs in some countries that have not had any nationally representative surveys, such as India and Malaysia. The extent to which $\mathrm{FGM} / \mathrm{C}$ is practiced varies greatly across regions within countries, and is most markedly associated with ethnicity. Increasingly, girls are undergoing $\mathrm{FGM} / \mathrm{C}$ at younger ages, with most cut before the age of 5 . The vast majority of girls are cut by traditional practitioners, and types I and II (clitoridectomy and excision) are the most common forms of cutting. Increasingly, women and girls in immigrant communities such as in the United Kingdom and in the United States, Canada, New Zealand, and Australia are affected by the practice.

Policies and programmes aimed at ending FGM/C must be attuned to the context in which the practice is embedded. Understanding the complex social norms and cultural value systems that often shape its meaning and significance is critical. Reasons given for the continuation of FGM/C vary across countries and cultures, and may change over time, though common rationales include: assurance of girls' or women's social status, chastity, or marriageability; religious identity; ritual marking of a transition to womanhood; maintenance of family honor and respect; and improvement of beauty and hygiene. Decisionmaking around FGM/C tends to be made within a broad social context, whereby the choices of parents or their daughters may be strongly influenced by other family or community members. Support for the practice is typically higher among those with less education, who live in rural areas, or who are from poor households. Despite these complexities, evidence in several countries shows that many men and women believe the practice should end, suggesting a promising window of opportunity for change.

The currently available data is rich in information that can inform policymakers and programmers about where to focus attention and how best to implement and strengthen current efforts for abandoning $F G M / C$. The data points to "hot spot" geographic areas, identifies populations that may be more amenable to change, and highlights drivers, rationales, and patterns of influence related to the practice that should be acknowledged and addressed within policy and programmatic strategies. This synthesis also highlights how FGM/C data collection, analysis, and interpretation could be improved to fill some key gaps in our understanding and further guide the way forward. 


\section{Introduction}

Female genital mutilation/cutting $(\mathrm{FGM} / \mathrm{C})$ is defined by the World Health Organization $(\mathrm{WHO})$ as "all procedures that involve partial or total removal of the external female genitalia, or other injury to the female genital organs for nonmedical reasons." WHO classifies FGM/C into four categories (see Box 1). Over the past couple of decades, this practice has increasingly been recognized as harmful to both the physical and psychological health of girls and women and a violation of human rights. In 2012 the United Nations (UN) General Assembly adopted an unprecedented resolution calling for global efforts to end FGM/C. ${ }^{1}$ Additionally, the UN Commission on the Status of Women and the African Union and European Union have publicly called for intensified efforts to eradicate FGM/C. Stakeholders worldwide now share the goal of ending FGM/C within a generation. National governments, grassroots organizations, researchers, and affected communities have made significant efforts toward achieving this vision. Twenty-seven countries in Africa and the Middle East where FGM/C is practiced have laws or decrees banning the practice (see Box 2); legal measures have also been passed in some other countries , primarily to protect girls in migrant families who come from practicing countries. Others have implemented a range of research, programmatic, and policy activities to both improve understanding of the practice and to accelerate its abandonment. Despite this progress, much work remains to be done.

\section{Box 1. FGM/C Classifications}

Complete typology with subdivisions:

Type I. Partial or total removal of the clitoris and/or the prepuce (clitoridectomy). When it is important to distinguish between the major variations of Type I mutilation, the following subdivisions are proposed:

- Type la. Removal of the clitoral hood or prepuce only.

- Type lb. Removal of the clitoris with the prepuce.

Type II. Partial or total removal of the clitoris and the labia minora, with or without excision of the labia majora (excision). When it is important to distinguish between the major variations of Type $\mathrm{II}$, the following subdivisions are proposed:

- Type Ila. Removal of the labia minora only.

- Type Illb. Partial or total removal of the clitoris and the labia minora.

- Type Ilc. Partial or total removal of the clitoris, the labia minora, and the labia majora.
Type III. Narrowing of the vaginal orifice with creation of a covering seal by cutting and appositioning the labia minora and/or the labia majora, with or without excision of the clitoris (infibulation).

- Type Illa. Removal and apposition of the labia minora.

- Type IIlb. Removal and apposition of the labia majora.

Type IV. All other harmful procedures to the female genitalia for nonmedical purposes, for example, pricking, piercing, incising, scraping, and cauterization.

Note: In French, the term "excision" is often used as a general term covering all types of female genital mutilation; in 2008, WHO slightly revised its classification system noting that ambiguities had arisen since it was first developed in 1995. The revised version attempts to address these shortcomings and includes subdivisions to better capture the variety of procedures.

Source: UNAIDS, UNDP, UNECA, UNESCO, UNFPA, UNHCHR, UNHCR, UNICEF, UNIFEM, WHO, Eliminating Female Genital Mutilation: Interagency Statement (Geneva: World Health Organization, 2008). 
To address FGM/C effectively, it is critical to fully understand its context and the dynamics of change. For example, those developing advocacy messages, programmatic interventions, or policies can benefit from knowing exactly how, when, and where the practice occurs. Moreover, it is important to be sensitive to the cultural significance it has, responsive to communities' concerns about abandonment, and cognizant of how and why decisions around cutting are made. This state-of-the-art synthesis includes data and information on these and other crucial FGM/C issues and presents a snapshot of the current state of affairs in easy-tounderstand, non-technical language.

This document complements several recent publications including: Female Genital Mutilation/Cutting: A Statistical Overview and Exploration of the Dynamics of Change, Estimates of Female Genital Mutilation/ Cutting in 27 African Countries and Yemen, and Demographic Perspectives on Female Genital Mutilation. ${ }^{2}$ Key figures and graphs from these documents have been adapted and updated whenever possible in light of newly available data. All of the graphs and figures in this report are derived using data from nationally representative surveys, primarily the Multiple Indicator Cluster Surveys (MICS) directed by UNICEF or the Demographic and Health Surveys (DHS) directed by ICF International (formerly Macro International). Since not all FGM/C-related questions have been asked consistently across surveys, graphs and figures reflect the most recently available data for the relevant data point.

The synthesis is intended primarily for governments, donors, and programmers - to help build an understanding of what we know now, so that effective actions can be taken toward accelerating the abandonment of $\mathrm{FGM} / \mathrm{C}$. The document also points to key gaps in our understanding that may be useful to researchers as well, and offers guidance on FGM/C data analysis and interpretation. Ultimately, the aim is to ensure that policies and programmes are informed by the best possible data and information.

\section{Box 2. FGM/C Affected Countries in Africa and the Middle East With Laws and Decrees Banning FGM/C}

$\begin{array}{lll}\text { Benin (2003) } & \text { The Gambia (2015) } & \text { Senegal (1999) } \\ \text { Burkina Faso (1996) } & \text { Ghana (2007)* } & \text { Somalia (2012) } \\ \text { Central African Republic (1996)* } & \text { Guinea (2000)* } & \text { South Africa (2005) } \\ \text { Chad (2003) } & \text { Guinea Bissau (2011) } & \text { Sudan (some states, 2008-09) } \\ \text { Côte d'Ivoire (1998) } & \text { Iraq (Kurdistan region) (2011) } & \text { Togo (1998) } \\ \text { Djibouti (2009)* } & \text { Kenya (2011)* } & \text { Uganda (2010) } \\ \text { Egypt (2008) } & \text { Mauritania (2005) } & \text { United Republic of Tanzania (1998) } \\ \text { Eritrea (2007) } & \text { Niger (2003) } & \text { Yemen (2001) } \\ \text { Ethiopia (2004) } & \text { Nigeria (2015) } & \text { Zambia (2005) }\end{array}$

*Note: Date indicates when an existing law was expanded.

Sources: Shell-Duncan, Bettina et al. 2013."Legislating Change? Responses to Criminalizing Female Genital Cutting in Senegal." Law \& Society Review 47(4): 803-35; Topping, Alexandra. 2015. "Nigeria's Female Genital Mutilation Ban Is Important Precedent, Say Campaigners." The Guardian. Retrieved August 5, 2015 (http://www.theguardian.com/society/2015/may/29/outlawing-fgm-nigeria-hugely-important-precedent-say-campaigners); and "FGM Ban begins a pivotal era for women and girls in the Gambia." United Nations Development Programme. Retrieved July 28, 2016 (http://www.undp.org/content/undp/en/home/blog/2016/2/5/FGM-ban-begins-a-pivotal-era-forwomen-and-girls-in-The-Gambia.html). 


\section{What Are the Main Sources of Data On FGM/C?}

Nationally representative data on $\mathrm{FGM} / \mathrm{C}$ for women and girls ages 15-49 have been collected in 29 countries, including 27 in Africa plus Yemen and Iraq (see Table 1). ${ }^{3}$ The two main data sources are the DHS and MICS. For Indonesia, nationally representative data on $\mathrm{FGM} / \mathrm{C}$ prevalence is available but only for girls under the age of 12 years. The data source is Riset Kesehatan Dasar (RISKESDAS - Basic Health Research Survey) implemented by the Indonesian Ministry of Health.

For the DHS and MICS, repeat surveys have been conducted in many countries approximately five years apart. Nearly all surveys ask women of reproductive age (ages 15-49) about their FGM/C status and circumstances surrounding the cutting, including age at cutting, type of cutting, and the identity of the person who performed the cutting. This self-reported data should be interpreted with caution given that disclosure might be affected by the sensitivity of the topic or its legal status. In addition, some women who were cut at a young age may not know or may be unaware of the specifics around who performed it and what type of FGM/C they experienced.

Most surveys also include additional questions about attitudes regarding the continuation of $\mathrm{FGM} / \mathrm{C}$ and, in some older surveys, reasons for the practice. In some countries, men have also been interviewed about their views regarding FGM/C. Since 2010, UNICEF and IFC International have used a standardized survey questionnaire, allowing for comparisons across surveys. This standardized module differs from earlier survey questionnaires in a number of ways: 1) Questions on the benefits or effects of $\mathrm{FGM} / \mathrm{C}$ for daughters have been removed because of difficulty in interpreting the responses; 2)The question on intention to have a girl undergo FGM/C has been removed; 3) Respondents are asked about the $\mathrm{FGM} / \mathrm{C}$ status of all living daughters, rather than just
Table 1. Most Recent FGM/C Data Sources for 30 Countries

\begin{tabular}{|c|c|}
\hline Country & Data source \\
\hline Benin & MICS 2014 \\
\hline Burkina Faso & DHS/MICS 2010 \\
\hline Cameroon & DHS 2004 \\
\hline Central African Republic & MICS 2010 \\
\hline Chad & MICS 2010 \\
\hline Côte d'Ivoire & DHS 2012 \\
\hline Djibouti & MICS 2006 \\
\hline Egypt & DHS 2014 \\
\hline Eritrea & DHS 2002 \\
\hline Ethiopia & DHS 2005 \\
\hline Gambia & DHS 2013 \\
\hline Ghana & MICS 2011 \\
\hline Guinea & DHS 2012 \\
\hline Guinea-Bissau & MICS 2014 \\
\hline Indonesia & RISKESDAS 2013* \\
\hline Iraq & MICS 2011 \\
\hline Kenya & DHS 2014 \\
\hline Liberia & DHS 2013 \\
\hline Mali & MICS 2015 \\
\hline Mauritania & MICS 2011 \\
\hline Niger & DHS 2012 \\
\hline Nigeria & DHS 2013 \\
\hline Senegal & DHS 2014 (continuous) \\
\hline Sierra Leone & DHS 2013 \\
\hline Somalia & MICS 2006 \\
\hline Sudan & MICS 2014 \\
\hline Togo & DHS 2013-14 \\
\hline Uganda & DHS 2011 \\
\hline United Republic of Tanzania & DHS 2010 \\
\hline Yemen & DHS 2013 \\
\hline \multicolumn{2}{|c|}{$\begin{array}{l}{ }^{*} \text { A nationally representative survey was administered } \\
\text { at the household level. Caregivers and guardians were } \\
\text { asked to report on the FGM/C status of all girls in the } \\
\text { household ages } 0-11 \text { years. }\end{array}$} \\
\hline
\end{tabular}


one daughter; and 4) Fewer questions are asked about opinions on FGM/C. A standardized module was also created for men, asking only 3 questions:

1) Have you ever heard of FGM/C?

2) Do you think the practice of $\mathrm{FGM} / \mathrm{C}$ is required by your religion?

3) Should the practice of $\mathrm{FGM} / \mathrm{C}$ continue or be stopped?

In this report, national prevalence is reported based on the most recent survey data. When prevalence is broken down along sociodemographic lines such as age, religion, or geographic region, we draw on data from the most recently available surveys that included that type of specific information.

\section{Where Is FGM/C Practiced and Among How Many?}

The prevalence-or proportion of all females ages 15-49 who report having been cut—varies widely across the 29 countries with nationally representative data. While less than 5 percent of women in Cameroon, Uganda, Niger, and Ghana have undergone FGM/C, the practice is nearly universal in Djibouti, Egypt, Guinea, Sierra Leone, and Somalia (see Figure 1). Two-thirds of all women who have undergone FGM/C live in just four countries: Egypt, Ethiopia, Nigeria, and Sudan (see Figure 2). More than one-quarter come from Egypt alone. ${ }^{4}$ While data on FGM/C among females ages 15-49 have not been collected in Indonesia, a 2013 survey shows that 49 percent of girls under age 12 have been cut. If similar or even higher rates apply to girls and women ages 15-49, Indonesia would have the highest concentration of women with FGM/C in the world. Further research is urgently needed to fill the current gaps in knowledge. Reports from Colombia, Iran, India, Malaysia, Oman, and Pakistan indicate that $\mathrm{FGM} / \mathrm{C}$ is practiced in these countries, however no nationally representative data are available. ${ }^{5}$

\section{Figure 1. Prevalence of FGM/C Among Girls and Women Ages 15-49, by Country}

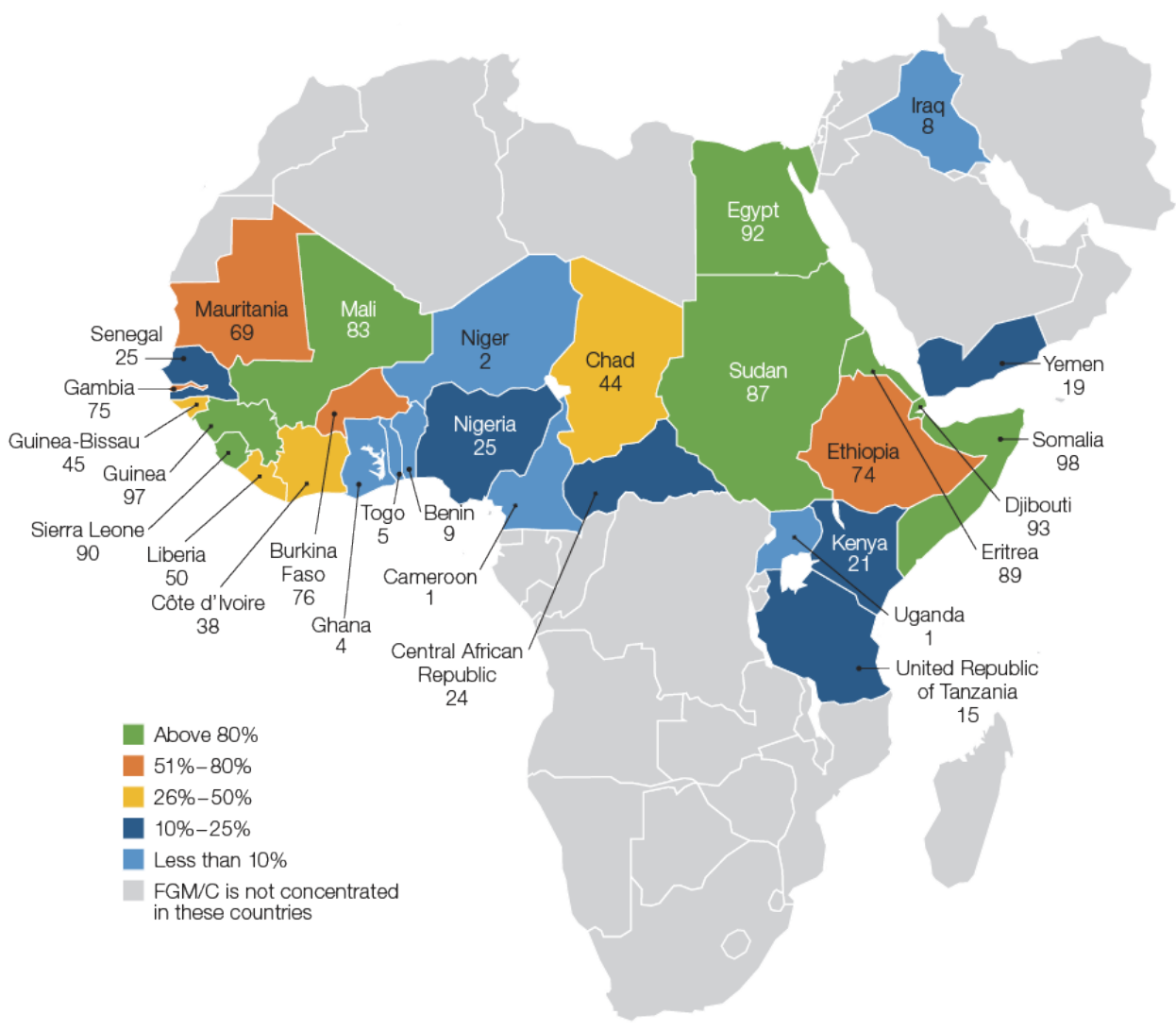




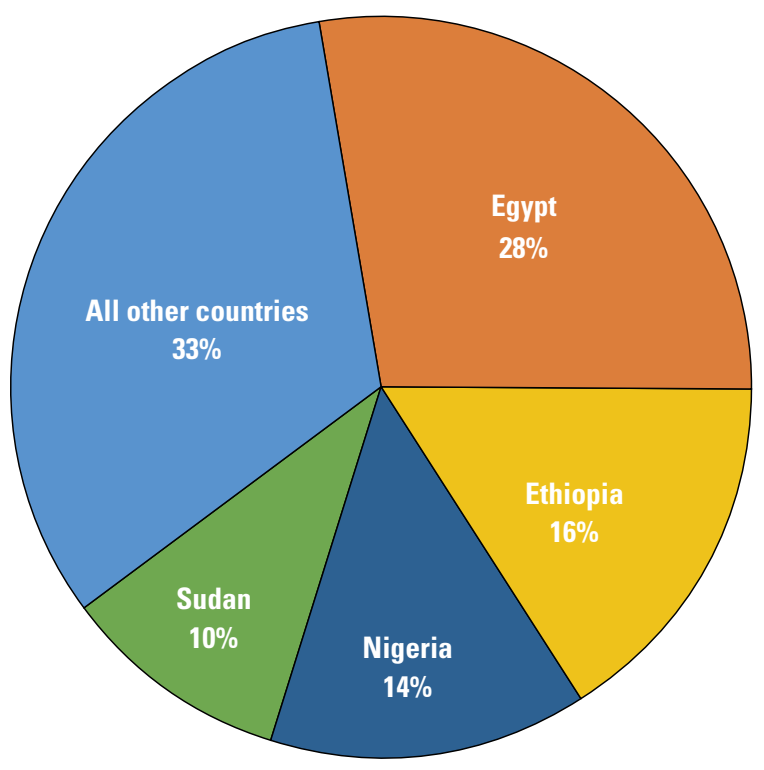

\section{Number of Girls and Women Affected by or at Risk of FGM/C}

Until recently estimates of the number of girls and women who have undergone FGM/C worldwide typically ranged from about 100 million to 140 million. ${ }^{6}$ In light of survey findings from Indonesia, the estimate has now been revised to at least 200 million. ${ }^{7}$ This figure should, however, be regarded with caution as many data gaps remain, for example, in countries where the practice reportedly occurs but where no data exist at all or where data do not exist for all relevant age groups. Improving data collection in such places is critical for creating a more reliable and complete picture of global dimensions of the practice.

In addition, the number of girls at risk of being cut has been similarly updated in the 30 countries with available data. New calculations show that nearly 70 million girls ages $0-14$ have been cut or may be at risk of being cut. ${ }^{8}$ More than half of these girls are from Egypt, Ethiopia, Indonesia, and Nigeria. According to UNICEF each year, about 3.6 million girls are at risk for FGM/C. Given that population growth rates are high in countries where $\mathrm{FGM} / \mathrm{C}$ is concentrated, the number of girls at risk each year could rise to 4.1 million by 2050 , even if current rates of decline remain constant. ${ }^{9}$ 


\section{Communities in the Diaspora}

Global migration patterns mean that even girls in non-FGM/C-practicing countries could be at risk if their parents or families still adhere to beliefs and practices from their home countries where $F G M / C$ is common. In the past few decades, Western Europe, the United States, Australia, and New Zealand have absorbed large numbers of migrants or refugees from practicing countries. A 2016 study by the Centers for Disease Control and Prevention estimates that in 2012 about 513,000 U.S. girls and women were at risk for FGM/C, meaning that they had potentially undergone the practice in the past or were at risk for undergoing it in the future. Of those at risk, about 169,000 , or 33 percent were younger than 18 years. ${ }^{10}$

Studies show that some girls in the European Union (EU) may also face the risk of FGM/C. According to a 2007 estimate, more than 125,000 women and girls in the United Kingdom (UK) and France (61,000 and 65,000 respectively) had undergone $\mathrm{FGM} / \mathrm{C}$ before arrival in the EU. An estimated 30,000 girls in the UK were at risk of cutting in that same year. ${ }^{11}$ Further work is underway to help fill the knowledge gaps that remain regarding $\mathrm{FGM} / \mathrm{C}$ in the diaspora, including up-to-date prevalence figures and information on how migration affects abandonment of the practice. ${ }^{12}$

\section{The Context Around FGM/C}

A large body of literature has documented considerable variation in when and how $\mathrm{FGM} / \mathrm{C}$ is performed. Studies have also shown recent changes in the nature of the practice.

\section{Age at Cutting}

In nearly half of the countries with information on age at cutting, the majority of girls were cut before the age of five (see Figure 3). Even in places where the practice commonly occurs at older ages, there has been a downward shift in the average age at cutting. According to 2014 DHS data in Kenya, older women (ages 40-44) report that they had been cut around age 15; however, the younger generation (ages 15-19) was cut on average around age 10 . Notably, age at cutting tends to vary across different ethnic groups within countries. In Kenya, FGM/C is performed, on average, between ages 9 to 16 .

One reason that $\mathrm{FGM} / \mathrm{C}$ is performed on girls at young ages is that it can be done more discretely, a particular advantage in areas where anti-FGM/C campaigns or legal restrictions are prominent. ${ }^{13}$ Other reported reasons are that younger girls heal more quickly and are less resistant. ${ }^{14}$

As the timing of $\mathrm{FGM} / \mathrm{C}$ shifts from adolescence to early childhood or even infancy, other changes sometimes follow. For example, cutting may be performed individually rather than in groups. In addition, it may lose its significance as a coming-of-age ritual and the healing period may no longer serve as a time of training or preparation for womanhood..$^{15}$ 
Figure 3. Age at Cutting Among Women Ages 15-49

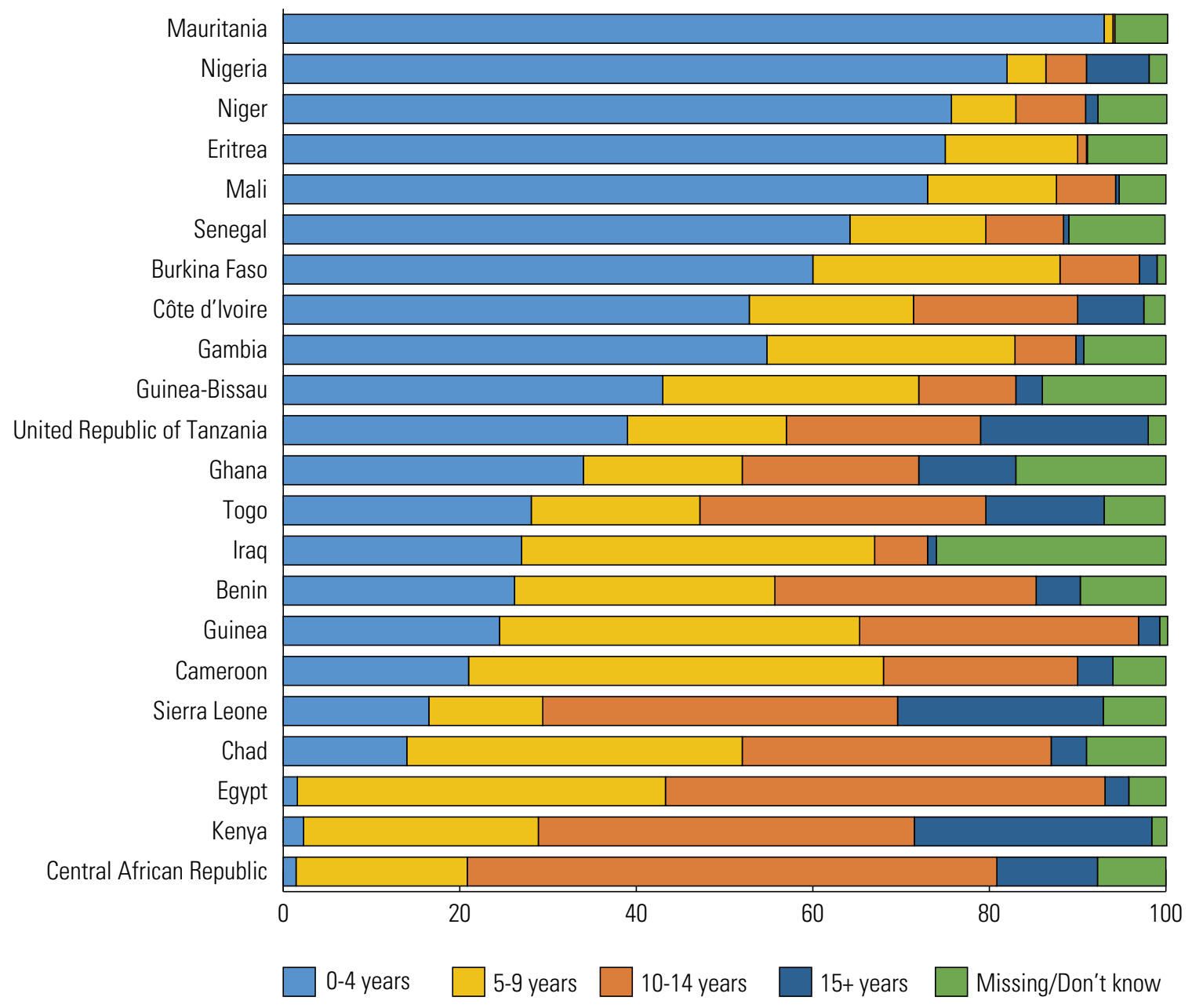

Adapted from UNICEF 2013, and updated with the most recent FGM/C data.

\section{Types of Cutting}

The DHS and MICS modules currently classify the type of cutting performed into four categories: 1) cut, no flesh removed; 2) cut, some flesh removed; 3) sewn closed; and 4) type not determined/ don't know/not sure. While these categories do not directly match the commonly used WHO typology (see Box 1), the category "cut, some flesh removed" corresponds most closely with Type I (clitoridectomy) and Type II (excision) combined. Meanwhile, "cut, sewn closed" corresponds to type III, infibulation, and "cut, no flesh removed" corresponds to type IV, a practice known as nicking or pricking. Based on the DHS/MICS classifications, the vast majority of girls and women who have been cut, have undergone Types I and II FGM/C, having had their genitalia cut, with some flesh removed (see Table 2). Knowing where infibulation is most concentrated, either at the national or subnational level, is of particular importance since infibulated women have the most specialized reproductive health needs. Three countries with the highest rates of infibulation are Eritrea (which also has the highest rate of nicking), Somalia, and Djibouti. 
Table 2. Type of Cutting Performed on Girls and Women Ages 15-49

\begin{tabular}{|l|c|c|c|c|}
\hline Country & Type of FGM/C & \multicolumn{2}{l|}{} \\
\hline Benin & Cut, no flesh removed & Cut, flesh removed & Sewn closed & $\begin{array}{c}\text { Type not determined, } \\
\text { don't know/not sure }\end{array}$ \\
\hline Central African Republic & 6 & 69 & 13 & 13 \\
\hline Chad & 20 & 70 & 7 & 3 \\
\hline Côte d'Ivoire & 10 & 80 & 7 & 3 \\
\hline Djibouti & 5 & 71 & 9 & 16 \\
\hline Eritrea & 6 & 25 & 67 & 2 \\
\hline The Gambia & 46 & 4 & 39 & 11 \\
\hline Ghana & 0 & 85 & - & 15 \\
\hline Guinea & 4 & 74 & 8 & 14 \\
\hline Guinea-Bissau & 6 & 84 & 8 & 3 \\
\hline Kenya* & 0 & 84 & 12 & 4 \\
\hline Mali & - & 86 & 8 & 2 \\
\hline Mauritania & 15 & 49 & 11 & 28 \\
\hline Niger & 4 & 69 & - & 8 \\
\hline Nigeria & 7 & 78 & 6 & 26 \\
\hline Senegal & 6 & 63 & 5 & 23 \\
\hline Sierra Leone & 14 & 51 & 12 & 10 \\
\hline Somalia & 1 & 72 & 17 & 4 \\
\hline Togo & 1 & 15 & 79 & 10 \\
\hline United Republic of Tanzania & 12 & 63 & 15 & 3 \\
\hline Yemen & 2 & 91 & 1 & - \\
\hline
\end{tabular}

Estimates are based on the most recent DHS and MICS data available as of March 2016. ${ }^{*}$ In the Kenya 2014 DHS, the question on type of FGM/C was asked differently than in previous surveys and differently than is currently asked in other countries. With regard to type of FGM/C, women were given two options: "sewn closed" or "not sewn closed." "Cut, no flesh removed" was not an option.

\section{Who Does the Cutting}

There are generally two types of FGM/C practitioners: health personnel (doctors, nurses, midwives, or any other trained personnel) and traditional practitioners (circumcisers, traditional birth attendants, or other traditional practitioners). In most countries, the vast majority of girls are cut by traditional practitioners (see Figure 4). 
Figure 4. Practitioners of FGM/C for Daughters Ages 0-14 Years

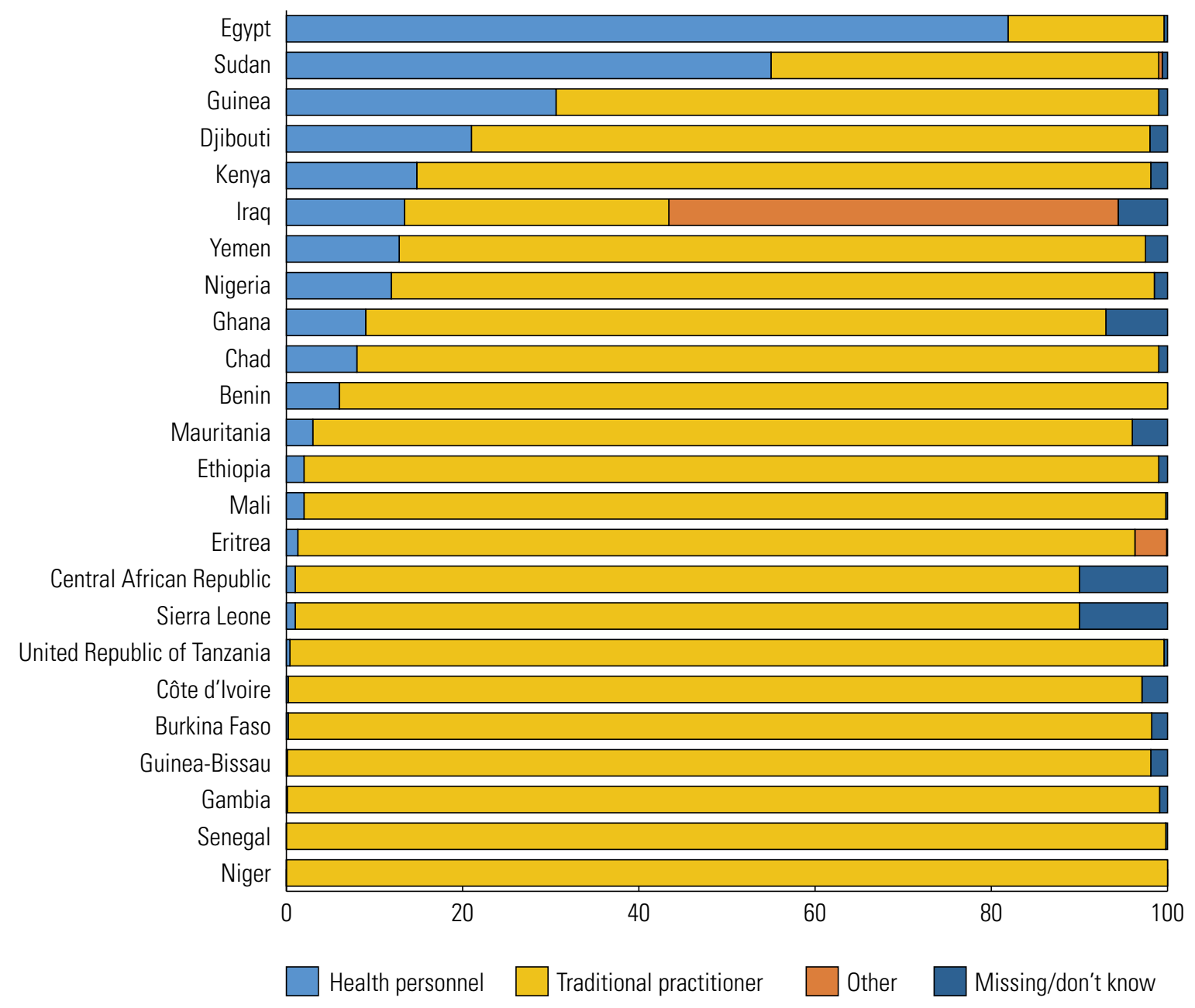

Adapted from UNICEF 2013, and updated with the most recent FGM/C data.

In countries where $\mathrm{FGM} / \mathrm{C}$ is increasingly becoming medicalized, such that the procedure is performed by health personnel, the intent may be to reduce potential health risks of what is perceived as an unavoidable practice. In Egypt, public policy related to medicalization has undergone many shifts over time. Although there has been a move away from it in recent years, it remains unclear whether or not doctors have stopped the practice (see Box 3). 


\section{Box 3. Shifts in Medicalization of FGM/C in Egypt}

In Egypt, the percentage of daughters cut by traditional practitioners has decreased steadily from 42 percent in 1995 to 18 percent in 2014. Meanwhile the percentage of girls cut by health personnel increased from 55 percent in 1995 to 82 percent in 2014. These trends occurred during a period of intense scrutiny and public debate about Egypt's official policy on medicalization of FGM/C. In 1994, in an effort to improve the safety of what was considered to be an "inevitable practice," Egypt's Ministry of Health issued a decree permitting only doctors in government hospitals to perform FGM/C. But in October 1995, this policy was reversed after women's rights activists critiqued it as an endorsement of $F G M / C$. State hospitals were then banned from performing FGM/C unless it was deemed medically necessary. In 2007, following the highly publicized death of an 11-year-old girl who was cut in a clinic, further restrictions banned all state-licensed health workers in either government or private clinics from performing FGM/C. In June 2008, the Egyptian parliament adopted a law imposing a sentence of a maximum of two years and a fine up to US\$1,000 for anyone performing FGM/C. A 2011 hospital-based study revealed that despite these legal restrictions, health care providers continued to perform FGM/C.

Sources: UNICEF. 2013. Female Genital Mutilation/Cutting: A Statistical Overview and Exploration of the Dynamics of Change. Ministry of Health and Population Egypt, El-Zanaty and Associates, and ICF International. 2015. "Egypt Demographic and Health Survey 2014" and Rasheed, Salah M., Ahmen H. Abd-Ellah, and Fouad M. Yusef. 2011. "Female Genital Mutilation in Upper Egypt in the New Millennium." International Journal of Gynecology and Obstetrics.

\section{Moving Beyond National Prevalence Data}

Understanding trends over time, sub- and cross-national differences, and sociocultural drivers of change can help determine whether policies and programmes are working, offer insight about where interventions can be used to accelerate change, or identify a need for research or inquiry to fill information gaps.

When showing changes over time, advocates often compare the prevalence of cutting among women ages 15-49 between surveys that are implemented five years apart. However, a better way to do this is to compare differences between the youngest (15-19) and oldest (45-49) age cohorts, as this gives a clearer indication of any changes that have occurred recently among the younger cohort. Using this approach, the data show little or no decline in $\mathrm{FGM} / \mathrm{C}$ in the past several decades in 15 countries, and some evidence of decline in 14 countries (see Box 4). Figure 5 shows the differences in these 14 countries, where declines range from about 7 percentage points in Egypt to 41 percentage points in Liberia.

\section{Box 4. Countries With and Without Evidence of Decline, Comparing 15-19 and 45-49 Age Cohorts}

15 countries with no decline

Cameroon

Chad

Djibouti

The Gambia

Ghana

Guinea

Guinea Bissau

Iraq

\section{4 countries with some evidence of decline}

Benin

Kenya

Burkina Faso Liberia

Central African Republic Mauritania

Côte d'Ivoire Nigeria

Egypt Sierra Leone

Eritrea Tanzania

Ethiopia Togo 
Figure 5. Comparison of FGM/C Prevalence Between 15-19 and 45-49 Year Age Cohorts in 14 Countries With Apparent Declines

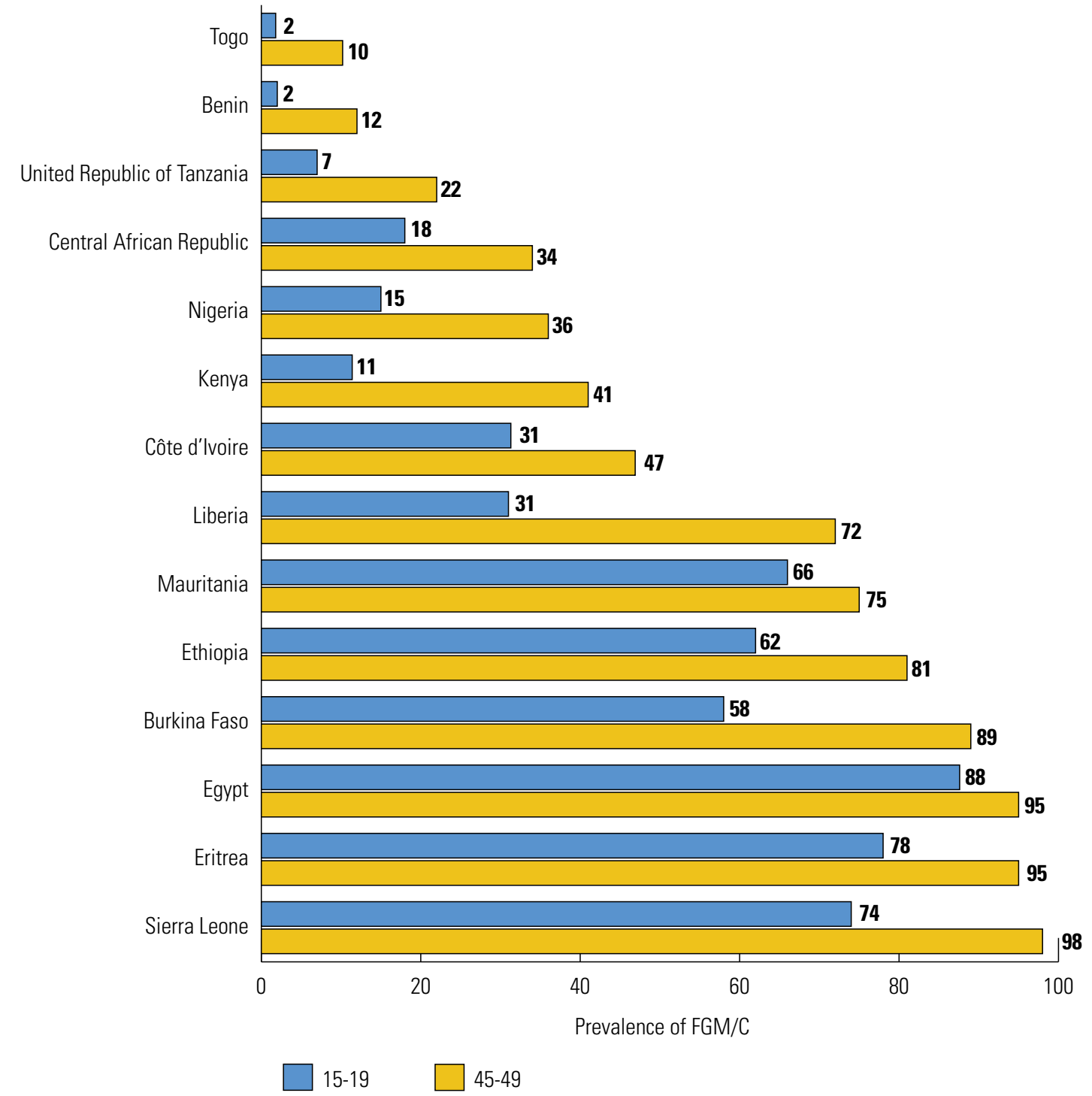

Adapted from UNICEF 2013, and updated with the most recent FGM/C data.

To determine when change began, the prevalence of FGM/C can be compared across age cohorts. When a marked difference in prevalence is only seen in the youngest cohort, it may reflect that the process of abandonment has begun somewhat recently. Meanwhile, progressive drops in prevalence across age cohorts indicate a more steady long-term decline. In half of the 14 countries with evidence of progress, the decline appears to be recent (see Figure 6). In the other half, change has occurred steadily over time (see Figure 7). In some cases, the change happened several decades ago and may have preceded the scaling up of $\mathrm{FGM} / \mathrm{C}$ abandonment efforts. The reason for these changes are not clear in many cases and more research is needed to explore the possible impact of broad social changes such as increases in girls' education, economic development, or women's empowerment. 
To further understand the timing of change, age at cutting must be considered. In Sierra Leone, for example, most girls are cut after age 10 during womanhood initiation ceremonies. A decline among 15-19 year olds, in this case, reflects very recent changes ( 5 to 9 years ago). In contrast, in Eritrea, most girls are cut during infancy and the drop in prevalence in 15-19 year olds reflects changes that would have occurred 15 to 19 years ago.

Another way to understand recent change in $\mathrm{FGM} / \mathrm{C}$ is to examine the prevalence among daughters ages 0 -14. This information is available from surveys conducted after 2010 and can help shed light on the impact of recent intervention efforts aimed at accelerating abandonment of FGM/C. Analysis and interpretation of this data, however, should take into account the fact that this cohort includes a mix of girls who: have been cut, are not cut but will be cut in the future, or will never be cut. This data contrasts the $15-49$ cohort, whose status is almost entirely final, since most cutting occurs before age 15 . For this reason, special statistical methods are needed to ensure more accurate analysis of daughter data. Such methods take into account the typical age of cutting in particular settings and the fact that current $F G M / C$ status may not reflect final status.

\section{Figure 6. Countries With Recent Declines in FGM/C Prevalence}

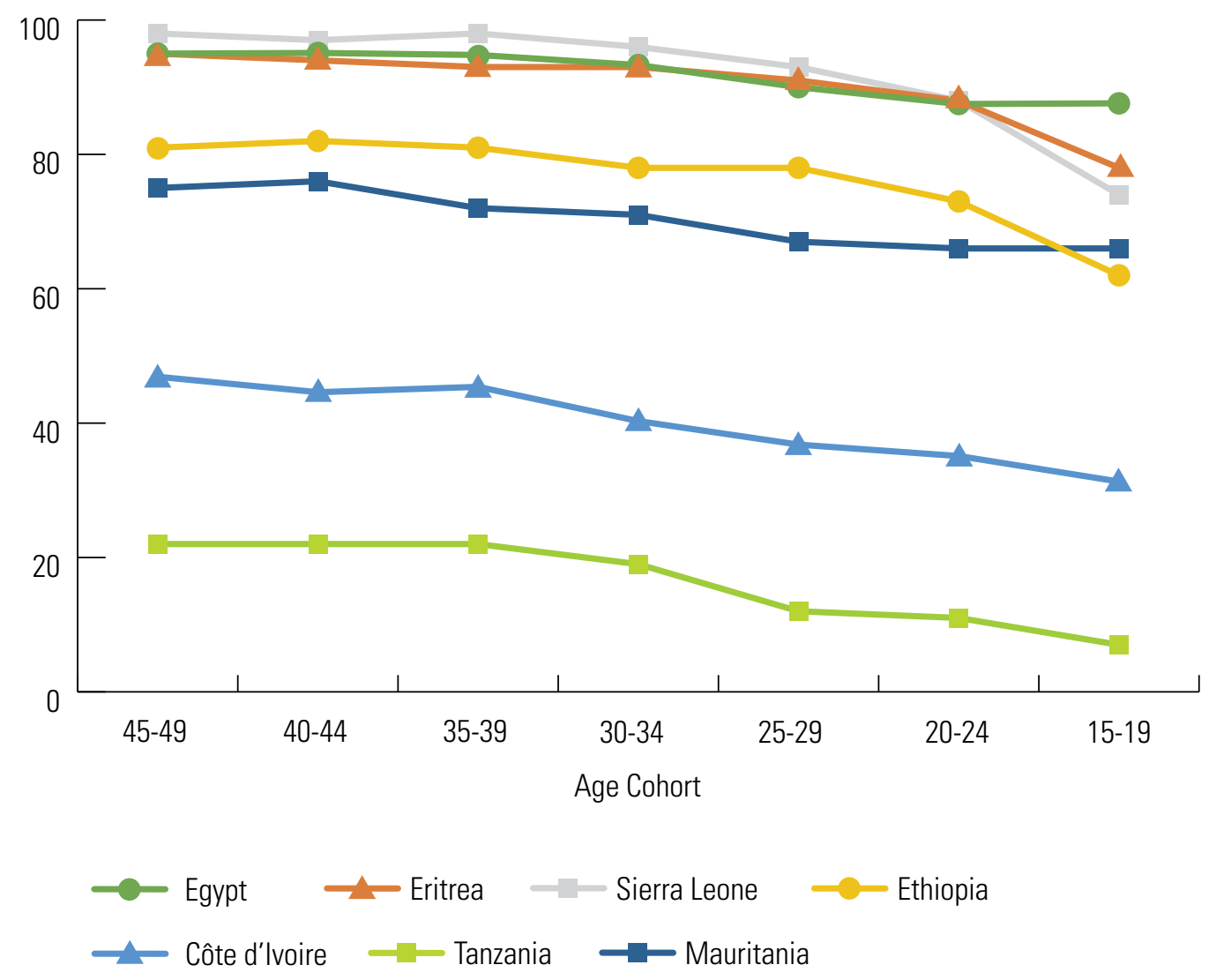


Figure 7. Countries With Steady Long-Term Declines in FGM/C Prevalence

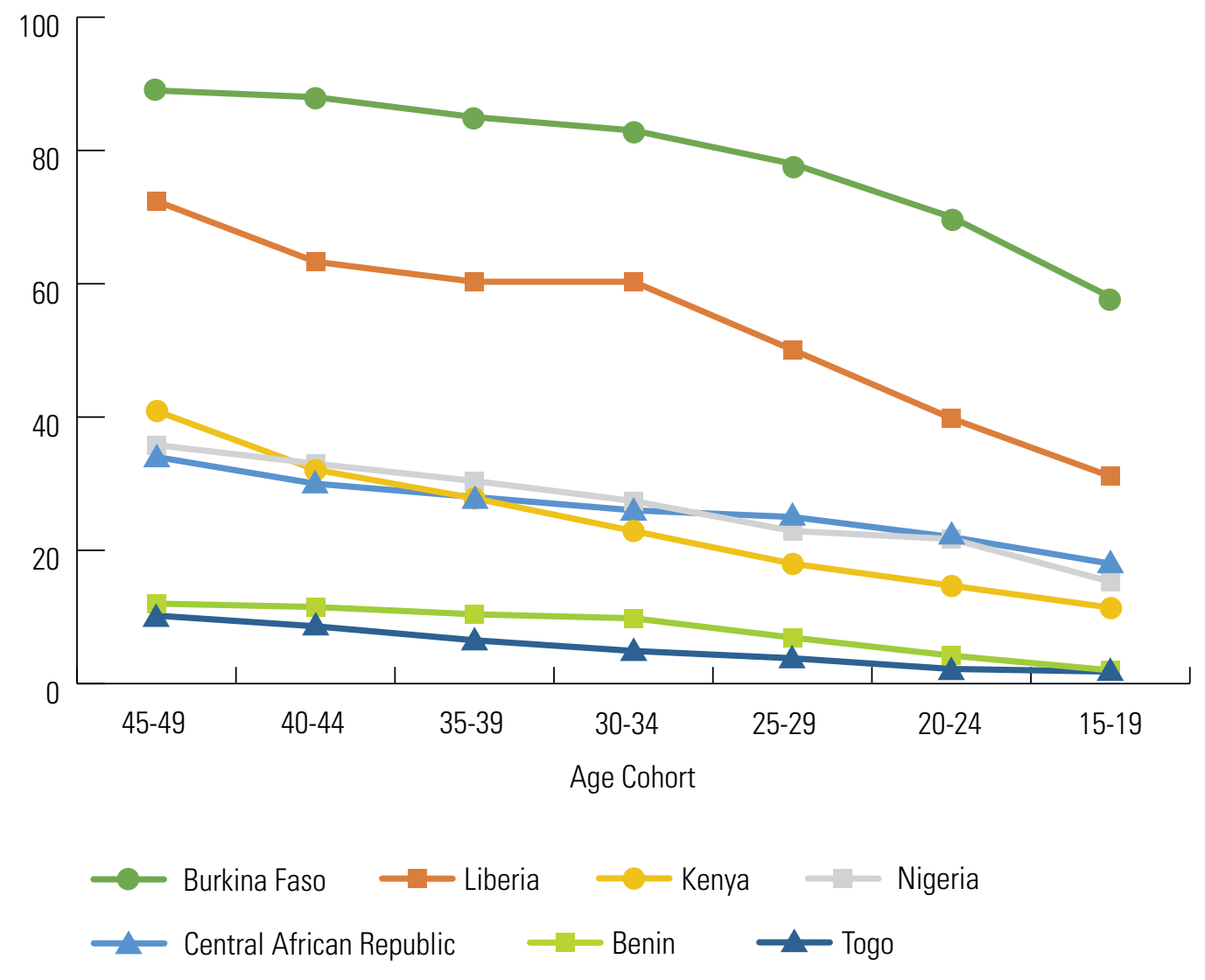

Estimates are based on the most recent DHS and MICS data available as of March 2016.

\section{National Prevalence Can Mask Subnational Differences}

While national FGM/C prevalence provides a useful overall picture of the situation in any given country, it can mask important and sometimes dramatic variations across sub-regions or ethnic groups. For example, in Kenya where prevalence is relatively low (21 percent), $\mathrm{FGM} / \mathrm{C}$ is distributed variably throughout the country, with prevalence ranging from 1 percent to 98 percent across provinces (see Figure 8). In Iraq, where national $\mathrm{FGM} / \mathrm{C}$ prevalence is even lower (8 percent), the practice is concentrated in just a few northern provinces. In two provinces, over half of women ages 15-49 have been cut (see Figure 9). 
Figure 8. FGM/C Prevalence Among Girls and Women Ages 15-49 in Kenya, by Province

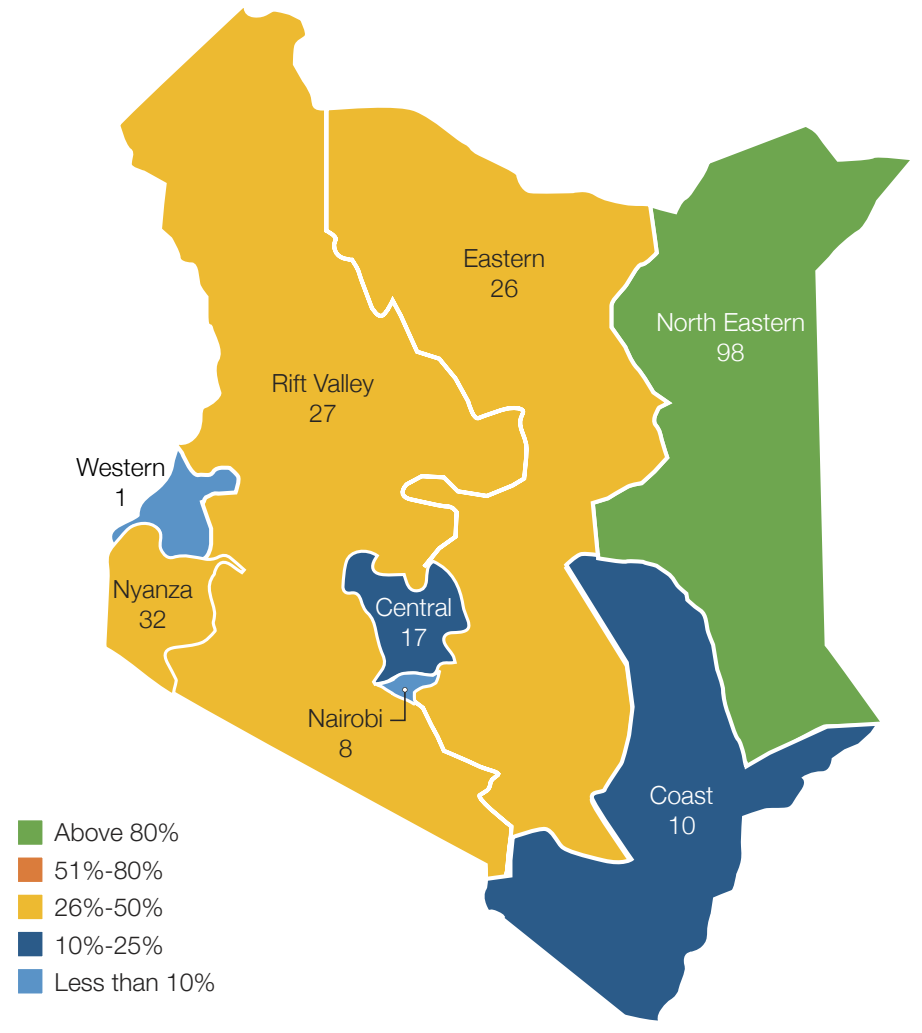

Estimates are based on the Kenya DHS, 2014

Figure 9. FGM/C Prevalence Among Girls and Women Ages 15-49 in Iraq, by Province

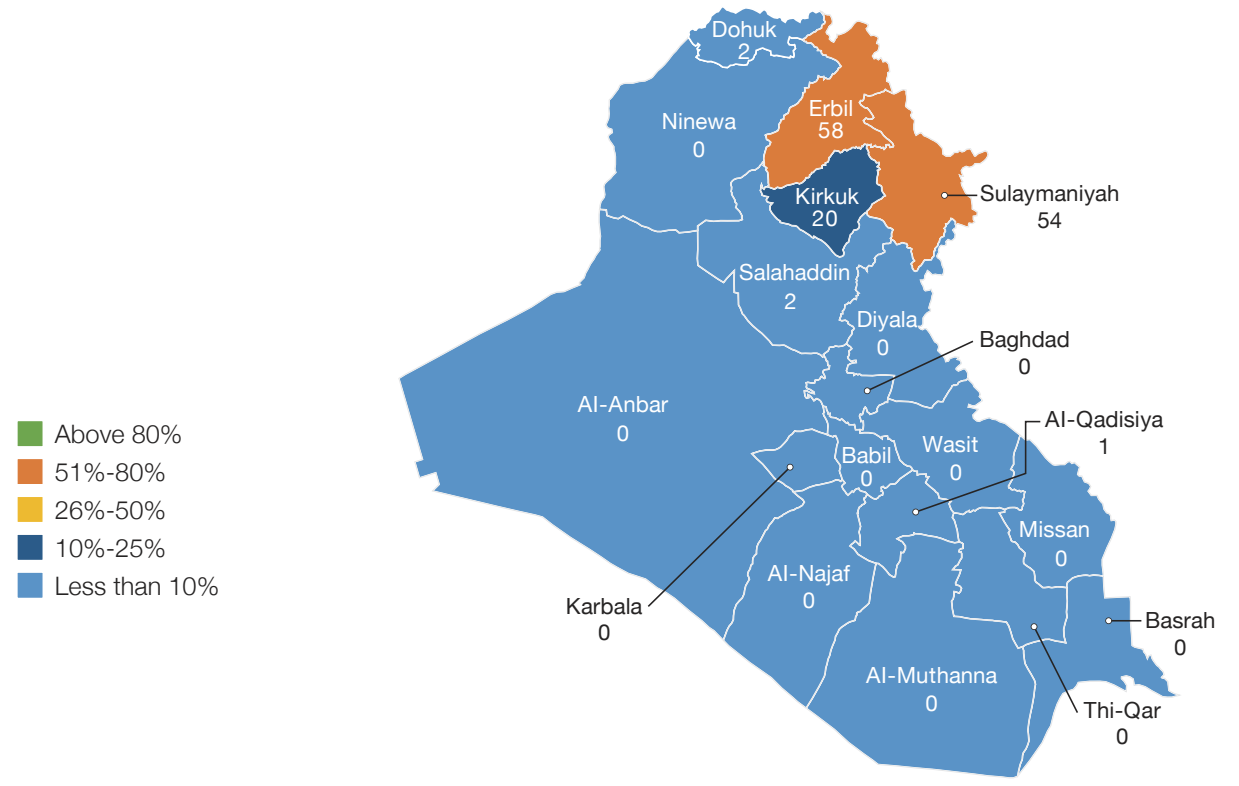

Adapted from UNICEF, Female Genital Mutilation/Cutting: A statistical overview and exploration of the dynamics of change, UNICEF, New York, 2013. 
FGM/C prevalence can also vary widely across different ethnic groups within a country. In The Gambia, where national prevalence is 76 percent, rates range from 12 percent among Wolof women to 97 percent among the Mandinka. Similarly, in Benin prevalence ranges from less than 1 percent among the Fon to 44 percent among the Bariba (see Figure 10). It is also worth noting that in some countries, there are communities in which the practice is anecdotally known to occur but relevant data is not available. In such cases, national and sub-national prevalence may not entirely reflect the true situation.

In addition, since national boundaries often cut across ethnic groups, prevalence among some communities may more closely mirror that of a similar ethnic group across the border than the national prevalence of their home countries. For example, the prevalence of FGM/C among ethnic Somalis living in Ethiopia is 97 percent and in Kenya it is 98 percent-both rates are more similar to the national prevalence in Somalia (99 percent) than to the national prevalence in either country (74 percent in Ethiopia and 21 percent in Kenya).

Figure 10. FGM/C Prevalence Among Girls and Women Ages 15-49 in Benin, by Ethnic Group

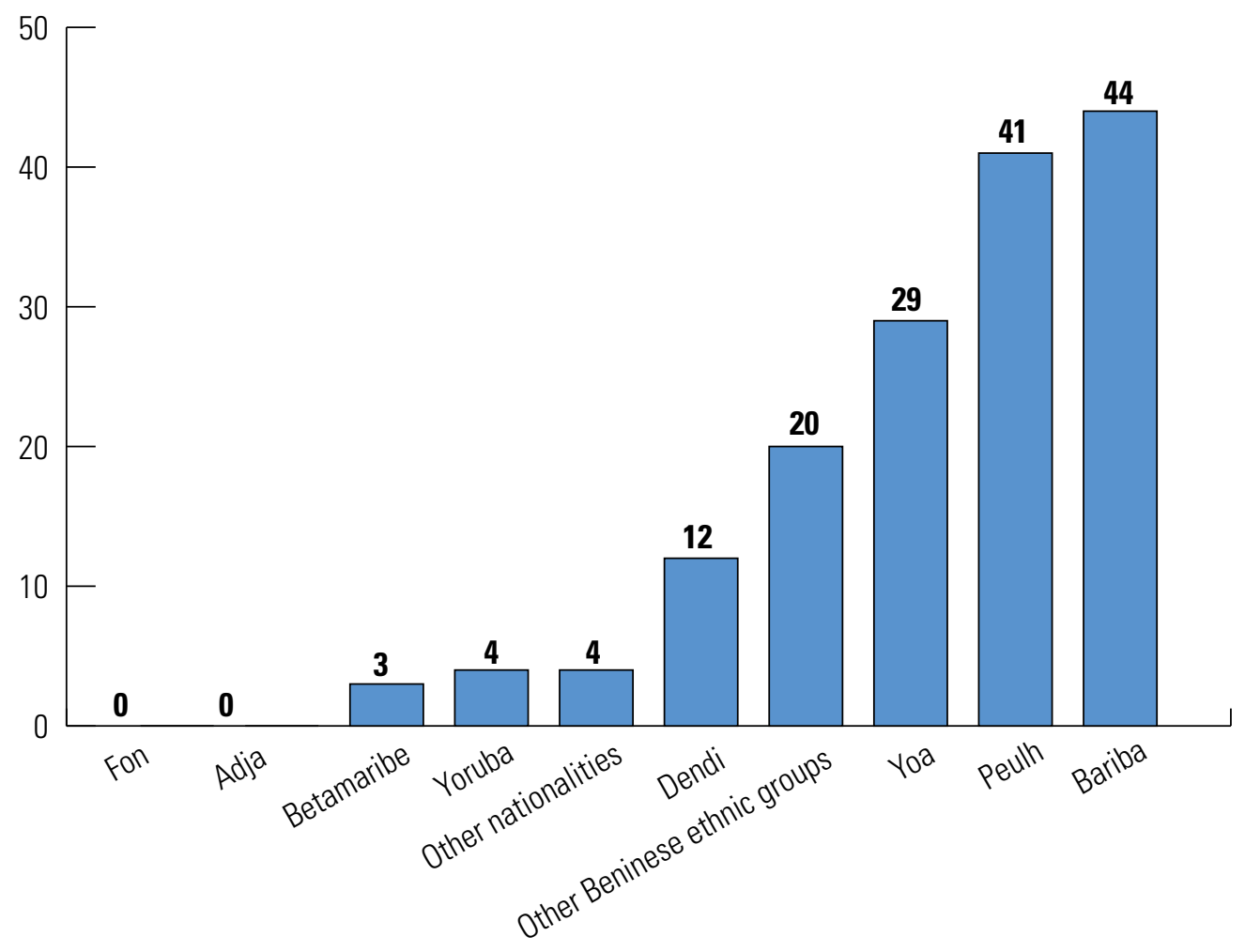

Estimates are based on the Benin DHS, 2011-2012. 
These ethnicity-related patterns illustrate an important aspect of $\mathrm{FGM} / \mathrm{C}$ - that it is a practice more strongly associated with ethnicity than any other personal characteristic. Ethnicity can be viewed as a proxy for shared norms or values concerning family honor, factors related to marriageability, sexual restraint, coming of age, or other codes of conduct. FGM/C often serves as a marker or symbol of these norms, which are often highly valued by some members of society and hence strongly protected. Therefore, advocates of abandonment must recognize that the practice may be deeply embedded within a community's identity and it can be difficult for individuals to embark on change alone. One researcher notes that "for most people ethnic identity is carefully guarded and markers of it are changed only when there are persuasive incentives." ${ }^{16}$

While many communities think that religion, particularly Islam, is one of the reasons FGMC is practiced, there is no linkage to religion. The practice pre-dates the birth of both Islam and Christianity and is not mandated by any religious scriptures. ${ }^{17}$ However, communities across the globe interpret their religions differently. Not all Muslim groups practice FGM/C; likewise some Christian groups and followers of traditional religions do (see Figure 11). Among the Mandingas in Guinea Bissau, $\mathrm{FGM} / \mathrm{C}$ is considered a prerequisite for ritual purity necessary to pray and is also viewed as a marker of belonging to an Islamic community. ${ }^{18}$ In contrast, members of Mandinga migrant communities in Portugal are exposed to modern Islam as well as modern Portuguese society and largely do not practice FGM/C.

These and other findings suggest that when the practice is linked to religion, it may be more strongly connected to culturally based social inclusion or as a symbol of the group's shared beliefs and values. Likewise, rationales associated with the practice can change over time. Advocates should acknowledge this fluidity and lack of uniformity across seemingly similar communities who may not necessarily share similar beliefs or interpret their religions the same way: Windows of opportunity for change may be identified within these dynamics. 
Figure 11. Prevalence of FGM/C Among Girls and Women Ages 15-49, by Religion

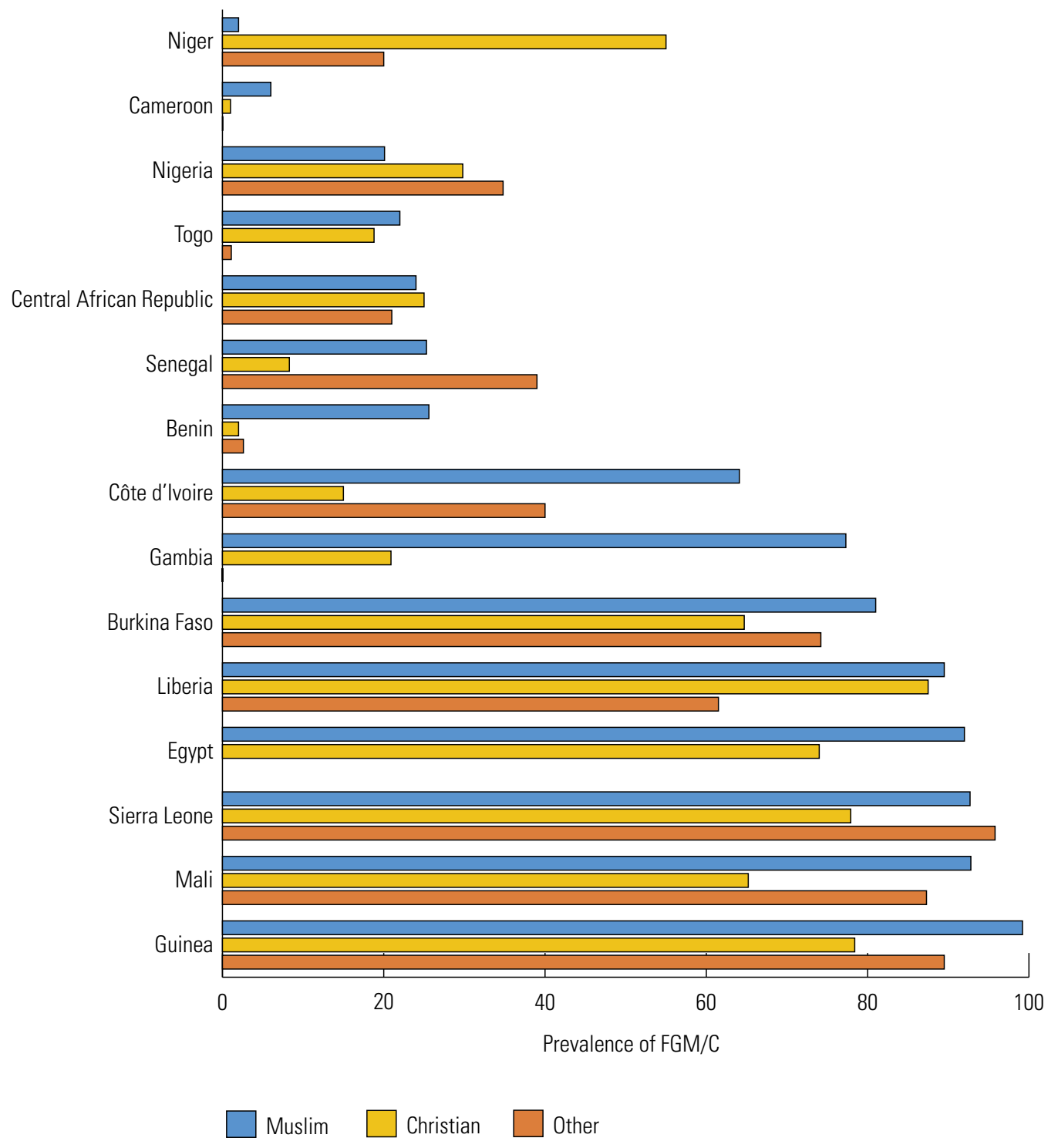

Estimates are based on the most recent DHS and MICS data available as of March 2016.

\section{FGM/C Is Embedded Within Complex Social Systems}

A keen understanding of the context in which FGM/C is embedded can help decisionmakers make appropriate choices for policies and interventions. So what do we know about the drivers and the decisionmakers around the practice? While some information gaps still exists around these issues, evidence shows that $\mathrm{FGM} / \mathrm{C}$ is embedded within complex sociocultural systems. It persists for a number of reasons that vary across countries and cultures. Despite the variations, common rationales for the practice are tied to a few key themes, including: assurance of girls' or women's social status, chastity, or marriageability; religious identity; ritual marking of a transition to womanhood; maintenance of family honor and respect; and improvement of beauty and hygiene..$^{19}$ Importantly, the rationale and significance attached to FGM/C within any given community are not static, as is often believed. Rather, as with other social norms or practices, they 
are dynamic and subject to change and influence over time. For example, in the 1940s in Guinea Bissau, FGM/C was strongly associated with marriageability. However, more recent accounts suggest that it is now more closely linked with concepts of personhood and religious identity. ${ }^{20}$

Some theories posit that a host of complex and interrelated factors are responsible for the continuation of the practice. One view is that behavior and decisionmaking around FGM/C are typically relational, meaning that the choices of one person or family are rarely made in isolation, but are dependent on expectations of families or communities and can affect social standing. As a result, the preferences of individuals can be overruled by those with greater power and authority-people who may feel greater pressure to adhere to social norms or who are influenced by others in their own networks. Thus, individuals or even single families who choose to abandon FGM/C can face high social costs, including exclusion from social support, events, and opportunities. ${ }^{21}$ One anthropologist from Sierra Leone says that had she chosen to forego initiation into a women's secret society, where the cutting is done, she would have been permanently relegated to the status of childhood by her extended family. ${ }^{22}$

In many communities, in countries as diverse as Sudan, Kenya, Sierra Leone, The Gambia, and Senegal, the $\mathrm{FGM} / \mathrm{C}$ preferences of girls or even their mothers are often superseded by those of elder women in the family or community. These matriarchs typically play the unspoken role of upholders of tradition and are in charge of the training, rituals, celebrations, and other activities associated with the practice, and as such, may be influential for introducing change. ${ }^{23}$ One study in The Gambia found that among already-cut mothers of at least one daughter, 70 percent felt unable to influence the opinions of other decisionmakers ${ }^{24}$ Further research is needed in other settings on the constellation of decisionmakers, social factors or experiences that influence their opinions, and the degree of influence they bring to the decisionmaking process.

\section{Opportunities for Abandonment}

Researchers have long studied influences that might present clues for abandonment of the practice, such as household wealth, urbanization, and education. Uncovering how the practice is situated within a larger social context provides an opportunity to assess factors driving the practice of $\mathrm{FGM} / \mathrm{C}$ and determine whether and how broader social change may open opportunities for abandonment. Do improvements in socioeconomic status and education, particularly for women, have far-reaching social and health effects, including a decline in $\mathrm{FGM} / \mathrm{C}$ ? It has been argued that effective change can occur only in the context of a women's movement directed at the social inequality of women, particularly economic dependency, educational disadvantage, and limited employment opportunities. Yet it is not fully understood exactly how social and economic factors affect the risk of $\mathrm{FGM} / \mathrm{C}$. Some experts suggest that numerous factors related to modernization may be influential, including the weakening of traditional family and power structures; an increase of women into the labor market; changes in women's economic and social roles and authority in decisionmaking; and shifts in their dependence on $\mathrm{FGM} / \mathrm{C}$ as a means to assure a secure future via marriage. ${ }^{25}$

In most countries where $\mathrm{FGM} / \mathrm{C}$ is practiced, support for its continuation is typically higher in rural than in urban settings, likely for a number of reasons. Rural areas are more likely to have kin-based communities with limited cultural diversity, making it difficult to deviate from longstanding social norms and conventions. Urban settings, by contrast, may be more culturally diverse, providing an opportunity to interact with a greater assortment of people, who may be both practicing and non-practicing. In urban settings, social ties may be broader and less linked to home communities, and negative social sanctions for non-adherence to FGM/C may be less common and effective. 
The role of economics in FGM/C is complex, but support for FGM/C is typically higher among those from poor households (see Figure 12). Older data from Sudan have shown that the middle class strongly adhere to infibulation and that elite or poor women more likely to alter or abandon $\mathrm{FGM} / \mathrm{C} .{ }^{26}$ More recently, in other settings, evidence suggests that economic development projects can have contradictory impacts on FGM/C, particularly if they do little to enhance women's autonomy and instead reinforce patriarchal relations and women's economic dependency. ${ }^{27}$

Numerous studies have documented a strong positive association between women's level of education, measures of health, and access to healthcare. Similarly, there is a strong link between women's education and the perpetuation of $\mathrm{FGM} / \mathrm{C}$. The data show that in high- and low-prevalence countries alike, daughters' risk of $\mathrm{FGM} / \mathrm{C}$ is generally highest among mothers with no education and tends to decrease substantially as mother's education goes up. However, the reasons for these associations are not well understood and merit further investigation. It could be that those with greater education have more exposure to intervention programmes and messages and are more amenable to receiving and accepting them. It may also be that the more-educated women participate less in the social networks of female relatives who might otherwise exert a strong influence on decisions regarding daughters' $\mathrm{FGM} / \mathrm{C}$.

Another area of study has been the influence of urbanization, education, and economic development on $\mathrm{FGM} / \mathrm{C}$ preferences and decisions made by individual women. However, as noted above, this individual-level focus overlooks the influence of the social networks and the broader social context that can shape, influence, and constrain the choices an individual makes. One finding from social network research is that interpersonal relationships often influence a person's behavior above and beyond their own attributes or personal preferences. ${ }^{28}$ Consequently, the influence of education or economic development on $\mathrm{FGM} / \mathrm{C}$ may come about indirectly through social ties and interactions that shape broader community norms and reduce barriers to change. In Egypt, for instance, recent reductions in girls' risk of undergoing FGM/C has been linked not just to the educational attainment of their own mothers, but more broadly to that of women throughout the community. These findings suggest that educational reforms and investments in girls' education a generation ago "may have an echo effect on girls' FGM/C risk a generation later." ${ }^{29}$ Further, structural interventions, such as educational reform policies and child marriage laws, can also have indirect, but potentially profound influences on FGM/C. These findings underscore the need for further research and a better understanding of the broader social, economic, and political climate that can affect the decisions that families make about FGM/C. 
Figure 12. Household Wealth and Support for the Continuation of FGM/C Among Girls and Women Ages 15-49

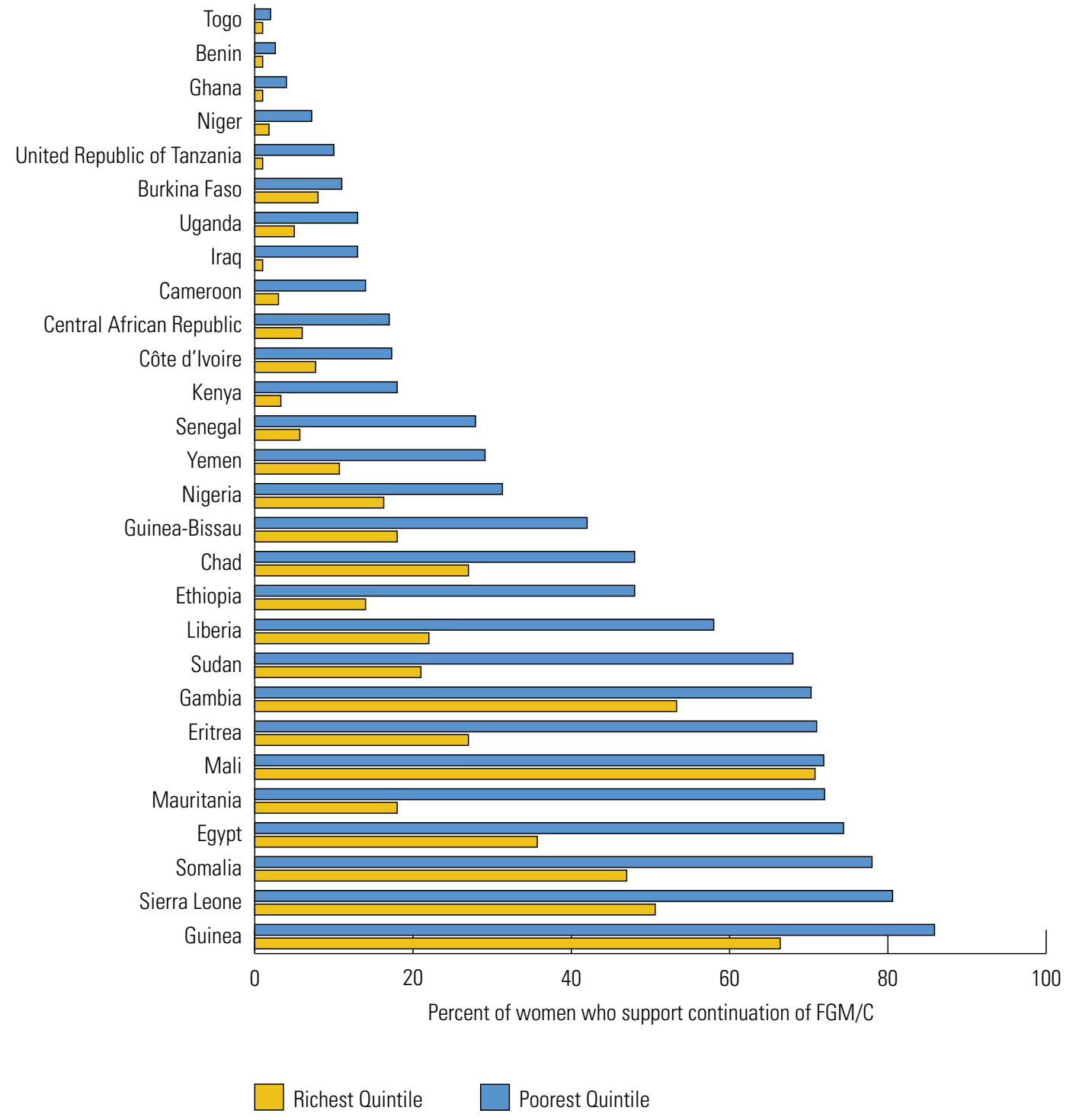

Adapted from UNICEF 2013, and updated with the most recent FGM/C data. 


\section{Is Support Shifting?}

Despite FGM/C's strong links to ethnicity and culture, there are several indicators that people in some communities are open to change and to potentially abandoning the practice. The latest data show that in many countries, the majority of already circumcised women report wanting $\mathrm{FGM} / \mathrm{C}$ to stop or are unsure whether it should continue (see Figure 13).

Figure 13. Girls and Women Ages 15-49 Who Are Cut but Open to Stopping FGM/C

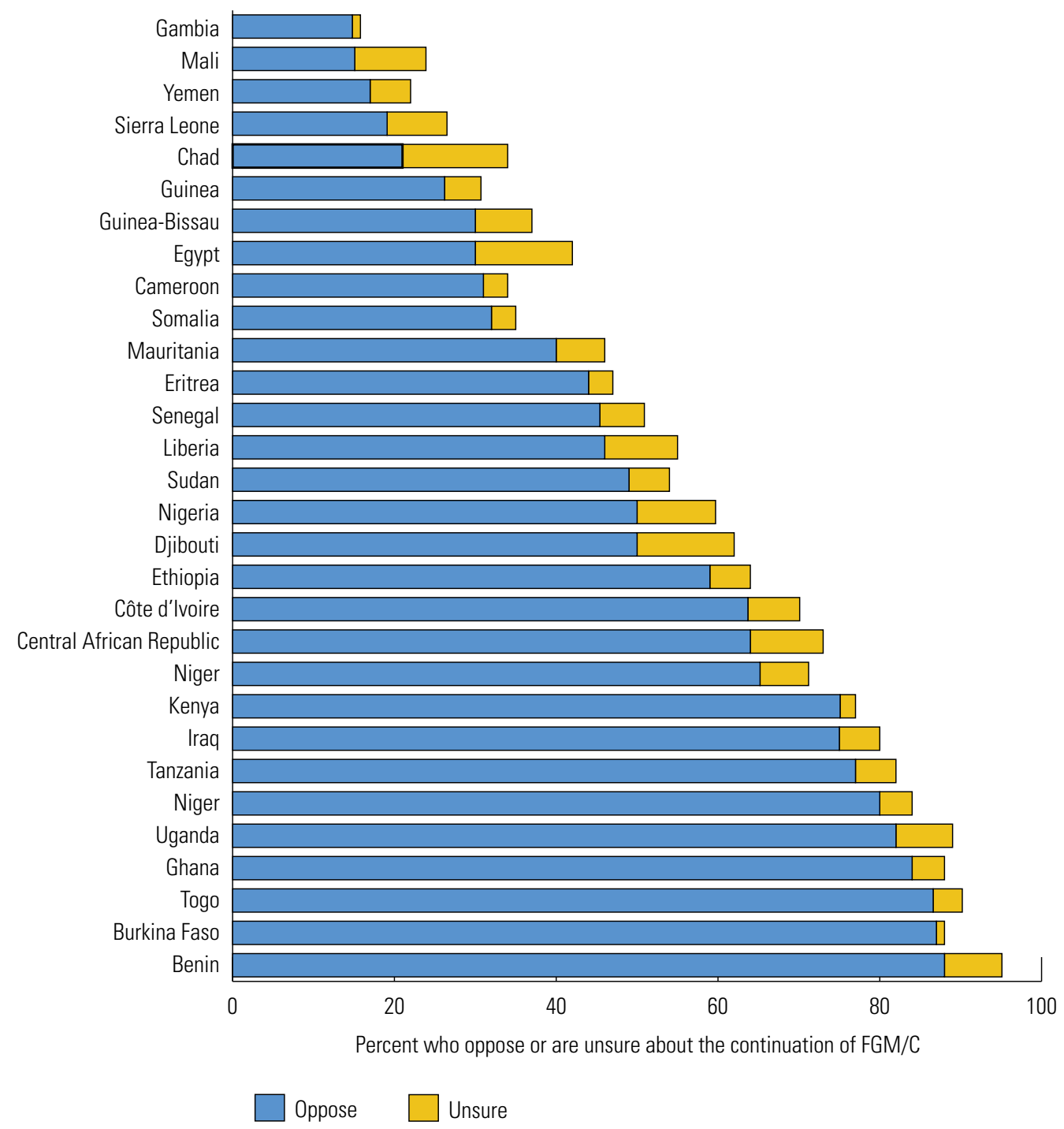

Adapted from UNICEF 2013, and updated with the most recent FGM/C data. 
Some mothers responded in surveys that they think FGM/C should stop and yet have daughters who are cut. A key question raised by this finding is: Why would women who no longer support FGM/C have their daughters cut? It is possible that despite favoring abandonment, they might proceed with the practice due to fear of violating social norms or being ostracized, limited influence on decisionmaking, or lack of awareness that others in the community may also share their views? It may also be the case that some daughters were cut prior to the mother's change in beliefs. Further research is needed to understand these crucially important aspects of the decisionmaking process.

$\mathrm{FGM} / \mathrm{C}$ is often thought to be a symbol of patriarchal oppression of women..$^{30} \mathrm{As}$ such, there is an expectation that support for the practice among men is high. The data, however, refute this. The majority of men in many countries report that they do not support the continuation of FGM/C (see Figure 14). In fact, in Eritrea, Guinea, Niger, Senegal, Sierra Leone, and Sudan, a smaller proportion of men than women report support for the continuation of $\mathrm{FGM} / \mathrm{C}$, raising some important questions: Do men participate in making decisions regarding FGM/C of girls? If so, what degree of influence do they have on the final outcome? Answers to these questions will help illuminate the decisionmaking process and whether men may be important allies in efforts to accelerate abandonment of FGM/C.

\section{Figure 14. In Most Countries Men Do Not Support Continuation of FGM/C}

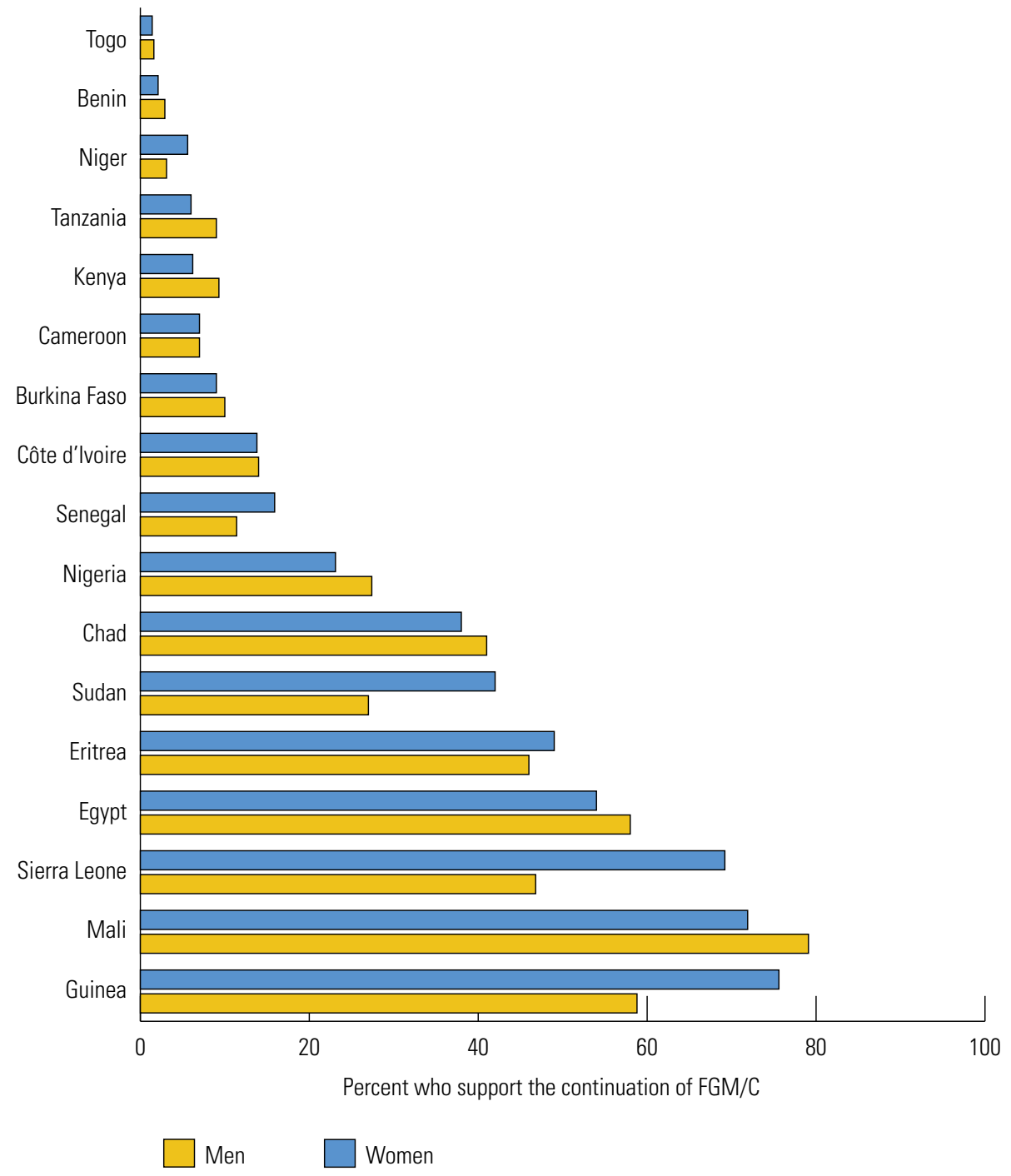


Data show that couples who live together are not always in agreement about the discontinuation of FGM/C, illustrating that prevailing social expectations around the practice may be called into question within families. ${ }^{31}$ An understanding of how decisions are negotiated may point to a window of opportunity for intervention. Crucial questions to explore might include: What influences some family members to shift their opinion regarding FGM/C? How are differences of opinion resolved? Do current intervention efforts strengthen the influence of people who favor abandonment?

Because of the complexity of $\mathrm{FGM} / \mathrm{C}$ and its connection to social norms and expectations, a chasm may exist between individual beliefs and actual behavior that could provide an opening to effect change. One conceptual model categorizes people into five categories with respect to readiness to abandon FGM/C: willing adherent, reluctant adherent, contemplator, reluctant abandoner, and willing abandoner (see Figure 15). ${ }^{32}$

\section{Figure 15. Dimensions of Readiness to Change}

\begin{tabular}{|c|c|c|c|}
\hline \multirow{2}{*}{ Behaviour } & \multicolumn{2}{|c|}{ Attitudes towards the practice } \\
\cline { 2 - 4 } & Thinks FGM/C should continue & Undecided & Thinks FGM/C should stop \\
\hline Adherent of FGM/C & Willing adherent & Reluctant adherent \\
\hline Undecided & & & \\
\hline Abandons FGM/C & Reluctant abandoner & & Willing abandoner \\
\hline
\end{tabular}

Adapted from Shell-Duncan, B . and Y. Hernlund, 'Are there "States of Change" in the Practice of Female Genital Cutting? Qualitative research findings from Senegal and the Gambia', African Journal of Reproductive Health, vol . 10, no . 2, 2006, pp 57-71.

In communities where most members are willing adherents of the practice, efforts to encourage abandonment may be met with considerable resistance. In contrast, where a sizeable proportion of people are willing abandoners, stable change has occurred and may continue, particularly with the encouragement of FGM/C abandonment interventions. The reluctant adherent category reflects a strong divide between personal beliefs and social expectations. It is possible that abandonment efforts in communities where this belief is relatively common may have a better chance of gaining momentum and social acceptance over time. Reluctant abandoners may also be an important group to work with as they may still have misgivings about their actions and their daughters could still be at risk of cutting. Future research is needed to investigate this possibility. 


\section{Conclusion}

Currently a wealth of data is available that can help inform both global and national efforts toward FGM/C abandonment. This information can help identify where and with whom to work, as well as provide insight about potential opportunities for accelerating change. While national data can provide a useful snapshot of the extent of the problem in a country, further analysis that compares age cohorts and takes into account age at cutting, as well as subnational variations by region or ethnicity can provide even greater insight about trends over time and population groups where the practice is concentrated. Careful analysis of data on daughters can also provide important information about the effectiveness of particular interventions.

Targeted approaches may be needed to reach communities that are most affected. Further, there are certain groups who may be more ready to change than others and may provide a starting or tipping point for abandonment. For example, partnering with a critical mass of reluctant adherents may help an intervention or campaign gain momentum and achieve success more quickly than trying to convince a community of willing adherents.

Available information suggests that $\mathrm{FGM} / \mathrm{C}$ is a practice that is intricately woven into the fabric of social networks and tied to important cultural norms and values that are not uniform across countries or communities. At the same time the rationales associated with the practice are dynamic and can change over time. Thus, gaining an understanding of the unique beliefs and deeper meanings ascribed to FGM/C within a community, patterns of influence and decisionmaking, as well as the ways these beliefs are changing, can offer insight about which community-based abandonment strategies would be most effective. At the same time, it is important to examine the social, political, and economic factors driving the continuation of FGM/C and further explore the ways that social reform strategies, such as legislation banning $\mathrm{FGM} / \mathrm{C}$ or policies on girls' education, can influence abandonment of the practice.

The data reveal that in a handful of countries the process of abandoning FGM/C is already underway. Additionally, in a few other countries, prevalence appears to be declining among the younger cohort of girls. The data also suggest that the decision to have a daughter undergo $\mathrm{FGM} / \mathrm{C}$ may not rest solely in the hands of mothers. Couples may have differences of opinion about the continuation of FGM/C and in many countries the majority of men are not in support of the practice. These findings point to a need to learn more about how decisions regarding FGM/C are made: Who participates in the decisionmaking process? How are differences of opinion resolved? Who holds the most influence in reaching a final decision, and who or which experiences or factors influence their opinions?

Despite the richness of the currently available information, some improvements to data collection, analysis, and interpretation are needed. Some suggestions are to:

- Encourage uniform data collection about FGM/C across countries using the updated $2010 \mathrm{FGM} / \mathrm{C}$ module.

- Expand the use of the FGM/C module to countries where FGM/C is reported to exist but where national data are unavailable.

- Conduct additional multivariate analyses to help build an understanding of the individual-, household- and community-level factors that may drive the practice. 
- Conduct analyses of FGM/C data among daughters ages 0-14 that take into account the fact that girls who are not currently cut, may still face a risk of being cut in the future.

- Conduct additional research to better understand decisionmaking around FGM/C.

- Improve upon the methods used to estimate the number of women in the diaspora who have been cut or the number of girls in the diaspora who are at risk.

Currently available data provide a strong foundation from which to launch and strengthen our efforts. Improvements to the way data are collected, analyzed, and interpreted in the future will further improve our understanding and help refine our approaches to $\mathrm{FGM} / \mathrm{C}$ abandonment. 


\section{References}

1 United Nations General Assembly. 2012. "Intensifying global efforts for the elimination of female genital mutilations." Retrieved August 8, 2015 (http://www.un.org/ga/search/view doc.asp? symbol=A/RES/67/146).

2 United Nations Children's Fund 2013," Female Genital Mutilation/Cutting: A statistical overview and exploration of the dynamics of change." New York, New York; Yoder, P. Stanley, Shanxiao Wang and Elise Johnson. 2013. "Estimates of female genital mutilation/cutting in 27 African countries and Yemen." Studies in Family Planning 44:2; and United Nations Population Fund 2015. "Demographic Perspectives on Female Genital Mutilation", New York, New York. UNFPA.

3 A survey conducted by the National Institute of Health Research and Development of the Ministry of Health reports FGM/C prevalence for girls ages 0-11 (51.2\%) in Indonesia, however data on national prevalence for girls ages 15-49 and data on other questions commonly asked in DHS or MICS surveys are not yet available.

4 Yoder, P. Stanley, Shanxiao Wang and Elise Johnson. 2013. "Estimates of female genital mutilation/cutting in 27 African countries and Yemen."

5 Al Himai, Habiba. 2014. "Female Genital Mutilation in the Sultanate of Oman." Retrieved July 30, 2015 (http:// www.stopfgm-mideast.org/wp-content/uploads/2014/01/habiba-al-hinai-female-genital-mutilation-in-the-sultanate-of-oman1.pdf)); Isa Rahman, Rashidah Shuib, and M. Shukri Othman. 1999. "The Practice of Female Circumcision among Muslims in Kelantan, Malaysia," Reproductive Health Matters 7(13): 137-144; United Nations Population Fund. 2011. "Project Embera-wera: An Experience of Culture Change to Eradicate Female Genital Mutilation in Colombia-Latin America." Retrieved March 8, 2013 (http://unfpa.org.co/uploadUNFPA/file/proyectomber.pdf); Rasheed Abdul Kahn, Sapna S. Patil, and Anita S. Valimalar. 2010. "The practice of female genital mutilation among the rural Malays in Northern Malaysia." The Internet Journal of Third World Medicine 9(1); Ahmady, Kameel. 2015 "A comprehensive research study of female genital mutilation/cutting in Iran." Retrieved July 30, 2015 (http:// kameelahmady.com/wp-content/uploads/Kameel\%20-\%20EN\%20Final.pdf); Ebrahim, Zefeen. 2012. "Women expose secret genital cutting rite." Retrieved July 20, 2015 (http://www.ipsnews.net/2012/01/pakistan-indiawomen-expose-secret-genital-cutting-rite/).

6 World Health Organization, "Female genital mutilation and other harmful practices: Prevalence of FGM." Retrieved August 14, 2015 (http://www.who.int/reproductivehealth/topics/fgm/prevalence/en/).

7 UNICEF. "Female Genital Mutilation/Cutting: A Global Concern." Retrieved July 5, 2016 (http://www.unicef.org/ media/files/FGMC 2016 brochure final UNICEF SPREAD.pdf).

8 This estimate for the number of girls at risk is derived from multiplying the estimate of the number of girls ages 0-14 by the prevalence of FGM/C in girls 15-19. For Indonesia only, data on prevalence are derived from 2013 survey data on FGM/C status among daughters ages 0-11 (RISKESDAS, 2013). This figure is applied to census data on the number of girls age 0-14 from the same year. Because it assumes a static prevalence of FGM/C (i.e.no decline), the calculation yields a high estimate.

9 United Nations Children's Fund. 2014. "Female Genital Mutilation/Cutting: What might the future hold?" New York, NY: UNICEF.

10 Goldberg, Howard, Paul Stupp, Ekwutosi Okoroh, Ghenet Besera, David Goodman, and Isabella Danel. 2012. “Female genital mutilation in the United States: Updated estimates of women and girls at risk." 2012. Public Health Reports, 131: 340-347. See also Population Reference Bureau, 2015. "Women and girls at risk of female genital cutting/mutilation in the United States." Retrieved July 31, 2015 (http://www.prb.org/Publications/Articles/2015/ us-fgmc.aspx).

11 Leye, Els, Lut Mergaert, Catarina Arnaut, and Sioban O'Brien Green. 2014. "Towards a better estimation of prevalence of female genital mutilation in the European Union: interpreting existing evidence in all EU Member States." Genus 70, no. 1. 
12 European Institute for Gender Equality. "Estimation of girls at risk of female genital mutilation in the European Union: Step-by-step guide." Retrieved on August 5, 2015. (http://eige.europa.eu/sites/default/files/documents/ MH0215093ENN Web.pdf).

13 Hernlund, Ylva. 2000. "Cutting without ritual and ritual without cutting: Female "circumcision" and the re-ritualization of initiation in The Gambia." in Female "Circumcision" in Africa: Culture, Controversy, and Change, eds. Shell- Duncan, Bettina \& Ylva Hernlund, Boulder, CO. Lynne Rienner Publishers; Bettina Shell-Duncan, et al. 2010. “Contingency and Change in the Practice of Female Genital Cutting: Dynamics of Decision Making in Senegambia." Seattle, Washington University of Washington, Center for Studies in Demography and Ecology; and Carolyne Njue and lan Askew. 2004. "Medicalization of female genital cutting among the Abagusii in Nyanza Province, Kenya: Frontiers in Reproductive Health Program." Washington, DC. Population Council.

14 Bettina Shell-Duncan et al. 2011. "Dynamics of change in the practice of female genital cutting in Senegambia: Testing predictions of social convention theory." Social Science and Medicine 73(8): 1275-1283.

15 Hernlund, Ylva. 2000. "Cutting without ritual and ritual without cutting: Female "circumcision" and the reritualization of initiation in the Gambia" in Female "Circumcision" in Africa: Culture, Controversy, and Change, eds. ShellDuncan, Bettina \& Ylva Hernlund. Boulder, C0; Carolyne Njue and lan Askew. 2004. "Medicalization of female genital cutting among the Abagusii in Nyanza Province." Kenya: Frontiers in Reproductive Health Program; and Yoder, P. Stanley and Mary Mahy 2001. "Female Genital Cutting in Guinea: Qualitative and Quantitative Research Strategies." DHS Analytical Studies No. 5 .Calverton, MD. ORC Macro.

16 Gruenbaum, Ellen. 2001. The Female Circumcision Controversy: An Anthropological Perspective. Philadelphia, PA. University of Pennsylvania Press.

17 Gruenbaum, Ellen. 2001. The Female Circumcision Controversy: An Anthropological Perspective. Philadelphia, PA. University of Pennsylvania Press.

18 Johnson, Michelle. 2000. "Becoming a Muslim, becoming a person: Female "circumcision," religious identity, and person- hood in Guinea-Bissau." in Female "Circumcision" in Africa: Culture, Controversy, and Change. eds. ShellDuncan, Bettina \& Ylva Hernlund. Boulder, CO. Lynne Rienner Publishers.

19 Gruenbaum, Ellen. 2001. "The Female Circumcision Controversy: An Anthropological Perspective" Female "Circumcision." in Africa: Culture, Controversy, and Change. Philadelphia, PA. University of Pennsylvania Press and Shell-Duncan, Bettina and Ylva Hernlund. 2001. "Female "Circumcision" in Africa: Dimensions of the Practice and Debates." in Female "Circumcision" in Africa: Culture, Controversy, and Change eds. Shell-Duncan, Bettina and Ylyva Hernlund. Boulder, CO. Lynne Rienner Publishers.

20 Johnson, Michelle. 2000. "Becoming a Muslim, becoming a person: Female "circumcision," religious identity, and person- hood in Guinea-Bissau." in Female "Circumcision" in Africa: Culture, Controversy, and Change. eds. ShellDuncan, Bettina \& Ylva Hernlund. Boulder, CO. Lyme Rienner Publishers.

21 Shell-Duncan, Bettina. 2010." Contingency and Change in the Practice of Female Genital Cutting: Dynamics of Decision Making in Senegambia." Seattle, Washington University of Washington, Center for Studies in Demography and Ecology and Shell-Duncan, Bettina. 2011. "Dynamics of change in the practice of female genital cutting in Senegambia: Testing predictions of social convention theory." Social Science and Medicine 73(8): 1275-1283.

Shell-Duncan, Bettina. 2011. "Dynamics of change in the practice of female genital cutting in Senegambia: Testing predictions of social convention theory." Social Science and Medicine 73(8): 1275-1283.

22 Ahmadu, Fuambai. 2000. "Rites and wrongs: An insider/outsider reflects on power and excision." in Female "Circumcision" in Africa: Culture, Controversy, and Change, eds. Shell-Duncan, Bettina\& Ylva Hernlund. Boulder, CO. Lynne Rienner Publishers. 
23 Thomas, Lynn. 2000. "Ngaitana (I will circumcise myself): Lessons from colonial campaigns to ban excision in Meru, Kenya." in Female "Circumcision" in Africa: Culture, Controversy, and Change. eds. Shell-Duncan, Bettina and Ylva Hernlund. Boulder, CO. Lynne Rienner Publishers; Shell-Duncan, Bettina. 2011. "Dynamics of change in the practice of female genital cutting in Senegambia: Testing predictions of social convention theory." Social Science and Medicine 73(8): 1275-1283; Aubel, Judi, Ibrahima Touré, and Mamadou Diagne. 2004. "Senegalese grandmothers promote improved maternal and child nutrition practices: the guardians of tradition are not averse to change." Social Science and Medicine. 59: 945-959; and Gruenbaum. 2001. "The Female Circumcision Controversy: An Anthropological Perspective."

24 Shell-Duncan, Bettina. 2000. "Becoming a Muslim, becoming a person: Female "circumcision," religious identity, and person- hood in Guinea-Bissau." in Female "Circumcision" in Africa: Culture, Controversy, and Change. eds. Shell- Duncan, Bettina \& Ylva Hernlund. Boulder, CO. Lynne Rienner Publishers.

25 Hayes, Rose Oldfield. 1975. "Female genital mutilation, fertility control, women's roles, and the patrilineage in modern Sudan: A functional analysis." American Ethnologist 2(4): 617-633; Hayford, Sarah. 2005. "Conformity and change: Community effects on female genital cutting in Kenya." Journal of Health and Social Behavior 46(2):121140; Kennedy, John. 1970. "Circumcision and excision in Egyptian Nubia." Man 5(2): 175-191; Modrek, Sepidah and Jenny X Liu. 2013." Exploration of pathways related to the decline in female circumcision in Egypt." BMC Public Health 13: 921-933; Van der Kwaak, Anke. 1992. "Female circumcision and gender identity: A questionable alliance?" Social Science and Medicine 35(6):777-787; and Yount, Kathryn. 2002. "Like mother, like daughter? Female genital cutting in Minia, Egypt." Journal of Health and Social Behavior 43: 336-358.

26 Balk, Deborah. 2000. "To marry and bear children? The demographic consequences of infibulation." in Female "Circumcision" in Africa: Culture, Controversy, and Change. eds. Shell-Duncan, Bettina and Ylva Hernlund. Boulder, CO. Lynne Rienner Publishers.

27 Gruenbaum, Ellen. 2001. "The Female Circumcision Controversy: An Anthropological Perspective." Philadelphia, PA. University of Pennsylvania Press.

28 Valente, T. W. 2010. "Social Networks and Health: Models, Methods, and Applications." New York, NY. Oxford University Press.

29 Modrek, S. and Liu, J. 2013. "Exploration of pathways related to the decline in female circumcision in Egypt." BMC Public Health 13:921-933.

30 Gruenbaum. 2001. "The Female Circumcision Controversy: An Anthropological Perspective."

31 United Nations Children's Fund. 2013. “Female Genital Mutilation/Cutting: A statistical overview and exploration of the dynamics of change." Retrieved July 5, 2016 (http://www.unicef.org/publications/index 69875.html).

32 Shell-Duncan, Bettina and Ylva Hernlund. 2006. "Are there "States of Change" in the Practice of Female Genital Cutting? Qualitative research findings from Senegal and the Gambia." African Journal of Reproductive Health. 10(2): 57-71. 


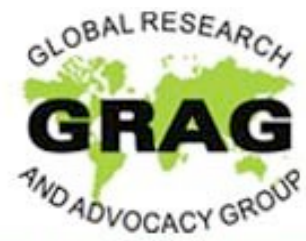

Leading Innovative Research

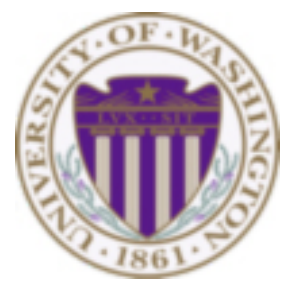

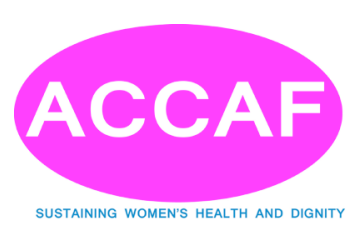
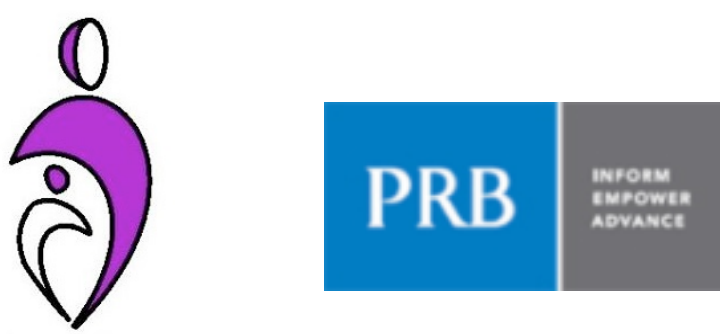

MannionDaniels 